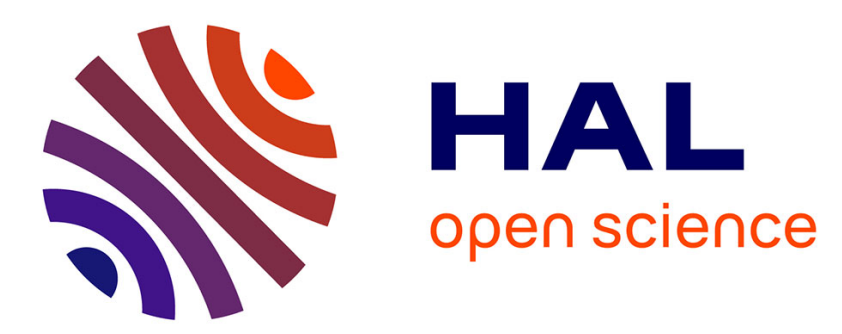

\title{
Turbulent liquid-liquid dispersion in SMV static mixer at high dispersed phase concentration
}

\author{
Emeline Lobry, Félicie Theron, Christophe Gourdon, Nathalie Le Sauze, \\ Catherine Xuereb, Thierry Lasuye
}

\section{To cite this version:}

Emeline Lobry, Félicie Theron, Christophe Gourdon, Nathalie Le Sauze, Catherine Xuereb, et al.. Turbulent liquid-liquid dispersion in SMV static mixer at high dispersed phase concentration. Chemical Engineering Science, 2011, vol. 66, pp. 5762-5774. 10.1016/J.CES.2011.06.073 . hal-00782653

\section{HAL Id: hal-00782653 https://hal.science/hal-00782653}

Submitted on 30 Jan 2013

HAL is a multi-disciplinary open access archive for the deposit and dissemination of scientific research documents, whether they are published or not. The documents may come from teaching and research institutions in France or abroad, or from public or private research centers.
L'archive ouverte pluridisciplinaire HAL, est destinée au dépôt et à la diffusion de documents scientifiques de niveau recherche, publiés ou non, émanant des établissements d'enseignement et de recherche français ou étrangers, des laboratoires publics ou privés. 


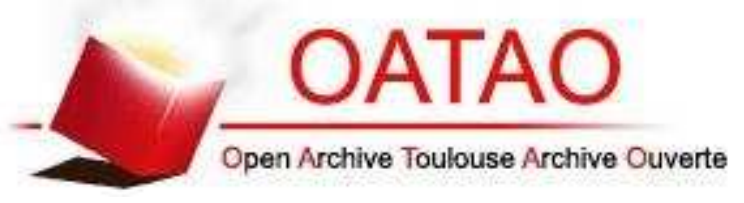

Open Archive Toulouse Archive Ouverte (OATAO)

OATAO is an open access repository that collects the work of Toulouse researchers and makes it freely available over the web where possible.

This is an author-deposited version published in: http://oatao.univ-toulouse.fr/ Eprints ID: 6189

To link to this article: DOI:10.1016/J.CES.2011.06.073

http://dx.doi.org/10.1016/J.CES.2011.06.073

\section{To cite this version:}

Lobry, Emeline and Theron, Félicie and Gourdon, Christophe and Le Sauze, Nathalie and Xuereb, Catherine and Lasuye, Thierry Turbulent liquid-liquid dispersion in SMV static mixer at high dispersed phase concentration. (2011) Chemical Engineering Science, vol. 66 (n² 23). pp. 5762-5774. ISSN 0009-2509

Any correspondence concerning this service should be sent to the repository administrator: staff-oatao@inp-toulouse.fr 


\title{
Turbulent liquid-liquid dispersion in SMV static mixer at high dispersed phase concentration
}

\author{
Emeline Lobry $^{\mathrm{a}, \mathrm{b}, *}$, Félicie Theron ${ }^{\mathrm{a}}$, Christophe Gourdon ${ }^{\mathrm{a}}$, Nathalie Le Sauze ${ }^{\mathrm{a}}$, \\ Catherine Xuereb $^{\mathrm{a}}$, Thierry Lasuye ${ }^{\mathrm{b}}$ \\ a Laboratoire de Génie Chimique, UMR CNRS 5503, Université de Toulouse, ENSIACET/INPT, 4 Allée Emile Monso, BP 84234, 31030 Toulouse Cedex 4, France \\ b SAV, Usine de Mazingarbe, BP49 62160 Bully les Mines, France
}

Keywords:

Emulsion

Multiphase flow

Static mixer

Surfactant

On-line Turbiscan

High dispersed phase concentration

\begin{abstract}
A B S T R A C T
The aim of this paper is to investigate the influence of physico-chemical parameters on liquid-liquid dispersion at high dispersed phase concentration in Sulzer SMV ${ }^{\mathrm{TM}}$ mixer. Four different oil-in-water systems involving two different surfactants are used in order to evaluate the effect of interfacial tension, densities and viscosities ratio on mean droplets size diameters. Moreover the influence of the dispersed phase concentration on the pressure drop as well as on the droplet size distribution is investigated. Two different droplets size distribution analysis techniques are used in order to compare the resulting Sauter mean diameters. The comparison between residence time in the mixer and surfactants adsorption kinetics leads to take into account the evolution of the interfacial tension between both phases at short times. Finally experimental results are correlated as a function of dimensionless Reynolds and Weber numbers.
\end{abstract}

\section{Introduction}

Liquid-liquid dispersions are often found in the process industry. They can take part to processes like liquid-liquid extraction, or reactions involving an emulsification step. They can also constitute consumable products such as in the food, cosmetic or drug industry. In both cases it is important to control the droplet size distribution and the mean diameter that could determine the final properties of the product.

Static mixers consist of a series of identical motionless elements inserted in a pipe, column or reactor. They redistribute the fluid in directions transverse to the main flow. The only energy cost depends on the power required for pumping. Generally, static mixers offer small space requirement, low equipment cost, short residence time and few maintenance constraints compared to other equipments. Even if they can be incorporated in pumparound loops in batch or semi-batch processes, this kind of device is naturally well adapted for continuous processes.

There is a wide variety of static mixers that are optimized for specific applications. Different designs are proposed depending on the flow regime and the applications. In their review Thakur et al. (2003) listed the principal commercial static mixer designs and their

\footnotetext{
* Corresponding author at: UMR CNRS 5503, Université de Toulouse, ENSIACET/INPT Laboratoire de Génie Chimique, 4 allée Emile Monso, BP 84234, 31030 Toulouse Cedex 4, France.

E-mail address: emeline.lobry@ensiacet.fr (E. Lobry).
}

different industrial applications including mixing of miscible fluids, thermal transfer and homogenization, and interface generation between two immiscible phases.

In the literature liquid-liquid dispersion in turbulent flows has been studied by many authors with different static mixer designs. The main encountered designs are the Kenics mixer (Middleman, 1974; Berkman and Calabrese, 1988; Lemenand et al., 2001, 2003, 2005; Yamamoto et al., 2007) and the SMX ${ }^{\mathrm{TM}}$ Sulzer mixer (Streiff, 1977; Streiff et al., 1997; Hirschberg et al., 2009; Theron et al., 2010; Theron and Le Sauze, 2011). Other mixers can be encountered but they are less documented and their use remains uncommon.

Most of the publications deal with dispersed phase concentrations lower than 0.25 (Middleman, 1974; Streiff, 1977; Matsumura et al., 1981; Al Taweel and Walker, 1983; Berkman and Calabrese, 1988; Al Taweel and Chen, 1996; Streiff et al., 1997; Legrand et al., 2001; Lemenand et al., 2001, 2003, 2005; Hirschberg et al., 2009; Theron et al., 2010). The effect of the dispersed phase ratio is never clearly studied except by Yamamoto et al. (2007) who worked on water-in-oil emulsions with a dispersed phase concentration ranging from 0.02 to 0.74 , and did not point out an effect of the dispersed phase concentration on the droplets size distribution.

Nowadays, the need to control continuous or batch processes has become more and more important. That is why on-line analysis measurements have been developed in addition to classical off-line ones. Among the parameters requiring controlling the mean droplets size measurement can be cited. The different techniques are based on optical visualisation, laser diffraction or 
acoustic principles. The technique can be chosen according to the physical properties of the system, the complexity of installation and the excepted results.

The advantages and drawbacks of the on-line droplet size analysis techniques are detailed in Table 1.

The SMV ${ }^{\mathrm{TM}}$ static mixer has been created in 1970 by the Sulzer Company. It consists of a stack of corrugated plates with a " $\mathrm{V}$ " shape. It is well known to perform gas-liquid and liquid-liquid dispersion for mass transfer, reaction or mixing and homogenisation of gas or liquid of low viscosity in turbulent flow. Curiously there is a lack of available information about liquid-liquid dispersion in Sulzer SMV static mixer. The only authors who reported emulsification's experiments in this type of mixers are Streiff (1977) and Streiff et al. (1997). Thus, the aim of this paper is to investigate the ability of this mixer to perform turbulent liquid-liquid dispersion, and especially at high dispersed phase concentration ( $\Phi=0.25-0.60$ in volume).

Four Water/Surfactant/Oil systems are chosen. The first part of this study deals with analysing the stability of emulsions obtained, and with comparing droplet size distributions obtained with two different techniques. These techniques are a classical off-line one based on laser diffraction and an on-line measurement based on light backscattering. Then the pressure drop is quantified for high Reynolds numbers for the different liquid-liquid systems, at same dispersed phase concentration. For the Water/PVA/Toluene system, the effect of the dispersed phase concentration on the pressure drop is evaluated. The effects of different parameters (dispersed phase concentration $\Phi$, flowrate and physico-chemical parameters) on the droplet size distribution are examined. Then the results are correlated in terms of Sauter mean diameter $d_{32}$ as a function of the mean energy dissipation rate and as a function of dimensionless numbers taking into account hydrodynamic and physico-chemical parameters.

The residence time in the static mixer is really short compared to the adsorption kinetics of the surfactants used to stabilize the droplets interface and to reach lower droplets sizes. A special attention is paid to the evolution of the interfacial tension value at short times.

\section{Materials and methods}

\subsection{Fluids}

Four different Water/Surfactant/Oil systems are used in order to evaluate the influence of physico-chemical parameters on the emulsification performances: Water/Tween80/Cyclohexane, Water/Tween80/Toluene, Water/PVA/Toluene and Water-Glycerol (25\% weight)/PVA/Toluene. Cyclohexane was purchased from Acros

Table 1

Comparison between different on-line droplets size measurement techniques.

\begin{tabular}{|c|c|c|c|}
\hline On-line Analysis technique & Experimental apparatus & Advantages & Drawbacks \\
\hline $\begin{array}{l}\text { Laser-induced fluorescence } \\
\quad \text { (Lan et al., 2006) }\end{array}$ & $\begin{array}{l}\text { - Laser and optical system } \\
\text { - Digital imaging system } \\
\text { - Liquid-liquid flow system }\end{array}$ & $\begin{array}{l}\text { - Measurement of in situ phase } \\
\text { volume fraction, drop size, drop } \\
\text { size distribution } \\
\text { - Non intrusive } \\
\text { - High dispersed phase ratio } \\
\text { (up to } 77 \% \text { vol.) }\end{array}$ & $\begin{array}{l}\text { - Fluorescent dye in the aqueous phase } \\
\text { - Lab scale technique } \\
\text { - Refractive index between the two phases }\end{array}$ \\
\hline $\begin{array}{l}\text { PVM (particle vision and } \\
\text { measurement) Lasentec } \\
\text { In situ video microscopy } \\
\text { (O'Rourke and } \\
\text { MacLoughlin, 2005) }\end{array}$ & $\begin{array}{l}\text { - } 10 \text { images per second } \\
\text { - Probe, light from } 6 \text { independent } \\
\text { laser sources, region of illumination } \\
2 \mathrm{~mm}^{2} \text {, lensing system, CCD array }\end{array}$ & - In situ measurement & $\begin{array}{l}\text { - } 3 \text { min to acquire the large number of images } \\
\text { necessary for representative measurements : } \\
\text { unsuitable for monitoring very rapid changes } \\
\text { in size distribution }\end{array}$ \\
\hline Optical methods & $\begin{array}{l}\text { - Endoscope: short focal distance, } \\
\text { covering tube to guarantee the } \\
\text { optical transparency between the } \\
\text { lens and the focus, fibber optic light } \\
\text { guide, CCD camera and software for } \\
\text { visualisation (Ritter and Kraume, } \\
\text { 2000) }\end{array}$ & - Local measurement & $\begin{array}{l}\text { - Transparent system, difference between the } \\
\text { refractive index of the two phases } \\
\text { - Large number of images must be acquired to } \\
\text { construct the resulting size distribution } \\
\text { - Time consuming }\end{array}$ \\
\hline $\begin{array}{l}\text { Phase Doppler } \\
\text { interferometry }\end{array}$ & - Laser light wavelength & $\begin{array}{l}\text { - Drop size and one component } \\
\text { of drop velocity }\end{array}$ & $\begin{array}{l}\text { - Unsuited to applications involving high } \\
\text { volume fractions of the dispersed phase }\end{array}$ \\
\hline $\begin{array}{l}\text { Laser backscattering } \\
\text { technique-focus beam } \\
\text { reflectance measurement } \\
\text { FBRM Lasentec }\end{array}$ & - Backscattered light & $\begin{array}{l}\text { - In situ and on line } \\
\text { measurement }\end{array}$ & - Chord length of detected particles \\
\hline $\begin{array}{l}\text { Optical reflectance } \\
\text { measurement (ORM) (Cull } \\
\text { et al., 2002) }\end{array}$ & $\begin{array}{l}\text { - Laser beam through a lens, rotating } \\
\text { beam intercept a drop, the light is } \\
\text { scattered back }\end{array}$ & $\begin{array}{l}\text { - In situ and on line } \\
\text { - Not limited by the dispersed } \\
\text { phase because laser beam } \\
\text { focused only at a short distance } \\
\text { away from the instrument }\end{array}$ & $\begin{array}{l}\text { - Chord length } \\
\text { - Calibration }\end{array}$ \\
\hline $\begin{array}{l}\text { Light backscattering } \\
\text { Turbiscan on-Line (Buron } \\
\text { et al., 2004; Pizzino et al., } \\
\text { 2009) }\end{array}$ & $\begin{array}{l}\text { - Measurement of the backscattered } \\
\text { intensity percentage }\end{array}$ & $\begin{array}{l}\text { - No dilution } \\
\text { - High dispersed phase ratio } \\
\text { - Non intrusive }\end{array}$ & $\begin{array}{l}\text { - Only the } d_{32} \\
\text { - Knowing the dispersed phase volume } \\
\text { fraction to obtain the } d_{32} \text { (and inversely) }\end{array}$ \\
\hline $\begin{array}{l}\text { Acoustic attenuation } \\
\text { spectroscopy (Boscher } \\
\text { et al., 2009) }\end{array}$ & $\begin{array}{l}\text { - Based on frequency -dependent } \\
\text { extinction of ultrasonic waves } \\
\text { arising from particles } \\
\text { - Droplet from } 1 \mu \mathrm{m} \text { to } 3 \mathrm{~mm}\end{array}$ & $\begin{array}{l}\text { - Concentrated systems } \\
\text { - On-line information: droplet } \\
\text { characteristics and volume } \\
\text { fraction of dispersed phase }\end{array}$ & - Difficulty to calibrate the system \\
\hline
\end{tabular}


Organics, Tween80 from Panreac, Glycerol and Toluene from Gaches Chimie and PVA from Nippon Gohsei. Properties of the different fluids are summed up in Table 2, where are also reported the density and viscosity ratio (respectively, $\rho_{d} / \rho_{d}$ and $\mu_{d} / \mu_{c}$ ), and the equivalent density of each system for a 0.25 dispersed phase concentration in volume. The equivalent density is calculated as follows:

$\rho_{e}=\phi \rho_{d}+(1-\phi) \rho_{c}$

The amount of surfactant used for each system is also precised in Table 2. These values are always higher than the critical micellar concentration (CMC).

Viscosity measurements are carried out using an AR 2000 rheometer (TA Instruments).

\subsection{Experimental rig and procedure}

Fig. 1 shows pictures of one Sulzer SMV element. Each element is made of 5 corrugated plates. The diameter and height of each element is about $10 \mathrm{~mm}$, which results in an aspect ratio $H / D \approx 1$. The diameter of each element $D$, the aspect ratio $D / H$ (element diameter/element length), the porosity $\varepsilon$ defined by expression (2), the hydraulic diameter $d_{h}$, and the crossbars thickness $\delta$ are given in Table 3

$\varepsilon=\frac{V_{\text {free for liquid flow }}}{V_{\text {apparent of the mixer }}}$

The schematic diagram presented in Fig. 2 illustrates the experimental rig used for emulsification experiments. It includes two feed tanks for the two phases involved in each system. The continuous phase feed tank is equipped with a mechanical stirrer in order to dissolve the surfactant in water and to homogenize the aqueous phase. Both phases are conveyed to the mixer thanks to gear pumps. The two phases enter the vertical stainless steel pipe containing the mixers through coaxial tubes. The dispersed phase enters the mixer through the central tube of $4 \mathrm{~mm}$ inner diameter. The mixer is made of 10 elements packed in the vertical steel pipe with a $90^{\circ}$ angle between each element.

All experiments are carried out at room temperature, i.e. between 20 and $23^{\circ} \mathrm{C}$.

The pressure drop generated by the flow through the mixer is measured with a differential pressure sensor (Rosemount). Mean droplet size is measured on-line thanks to the On-line Turbiscan which principle is explained further. The measurement cells of the apparatus are located downstream the static mixer. A sampling valve is also located at the mixers outlet.

The dispersed phase concentration in volume $\Phi$ is fixed thanks to respective phases flowrates as follows:

$\phi=\frac{Q_{d}}{Q_{d}+Q_{c}}=\frac{Q_{d}}{Q_{\text {tot }}}$

where $Q_{d}, Q_{c}$ and $Q_{\text {tot }}$ are, respectively, the dispersed phase, continuous phase and total volume flowrates.
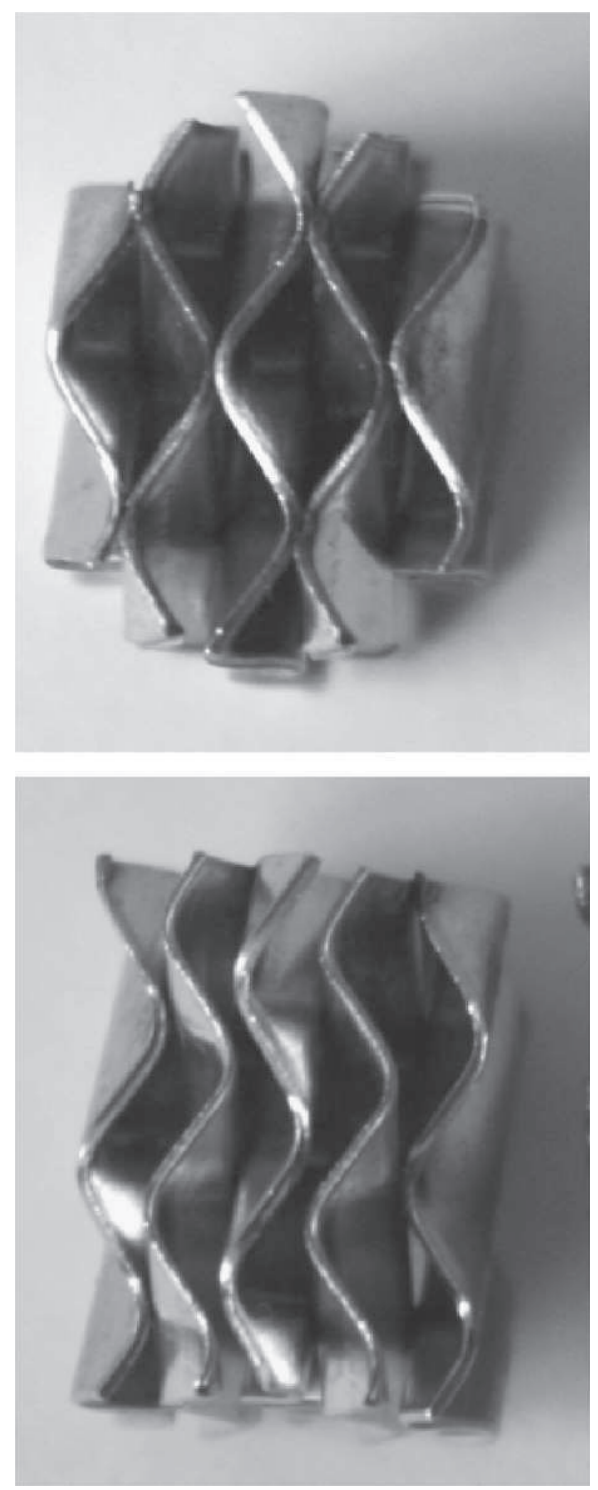

Fig. 1. Pictures of one element of the SMV mixer used.

Table 3

Geometrical data of the SMV mixer.

\begin{tabular}{lllll}
\hline$D(\mathrm{~mm})$ & $D / H$ & $\varepsilon$ & $d_{h}(\mathrm{~mm})$ & $\delta(\mathrm{mm})$ \\
\hline 10 & 1 & 0.83 & 3.5 & 0.14 \\
\hline
\end{tabular}

Table 2

Physico-chemical properties of fluids used.

\begin{tabular}{|c|c|c|c|c|}
\hline System & $S_{1}:$ Water/Tween80/Cyclohexane & $S_{2}:$ Water/Tween80/Toluene & $S_{3}:$ Water/PVA/Toluene & $S_{4}$ : Water-Glycerol $25 \% \mathrm{~m} / \mathrm{PVA} /$ Toluene \\
\hline$\rho_{c}\left(\mathrm{~kg} \mathrm{~m}^{-3}\right)$ & 995 & 995 & 997 & 1051 \\
\hline$\rho_{d}\left(\mathrm{~kg} \mathrm{~m}^{-3}\right)$ & 770 & 870 & 870 & 870 \\
\hline$\rho_{e}\left(\mathrm{~kg} \mathrm{~m}^{-3}\right)$ & 939 & 964 & 965 & 1006 \\
\hline$\rho_{d} / \rho_{c}$ & 0.77 & 0.87 & 0.87 & 0.83 \\
\hline$\mu_{c}($ Pa s) & 0.001 & 0.001 & 0.001 & 0.0021 \\
\hline$\mu_{d}$ (Pa s) & 0.00094 & 0.0059 & 0.00059 & 0.00059 \\
\hline$\mu_{d} / \mu_{c}$ & 0.94 & 0.59 & 0.59 & 0.28 \\
\hline Surfactant concentration & $\begin{array}{l}1.5 \% \text { in vol of the } \\
\text { continuous phase }\end{array}$ & $\begin{array}{l}1.5 \% \text { in vol of the } \\
\text { continuous phase }\end{array}$ & $\begin{array}{l}0.07 \% \text { in mass of the } \\
\text { dispersed phase }\end{array}$ & $\begin{array}{l}0.07 \% \text { in mass of the } \\
\text { dispersed phase }\end{array}$ \\
\hline
\end{tabular}




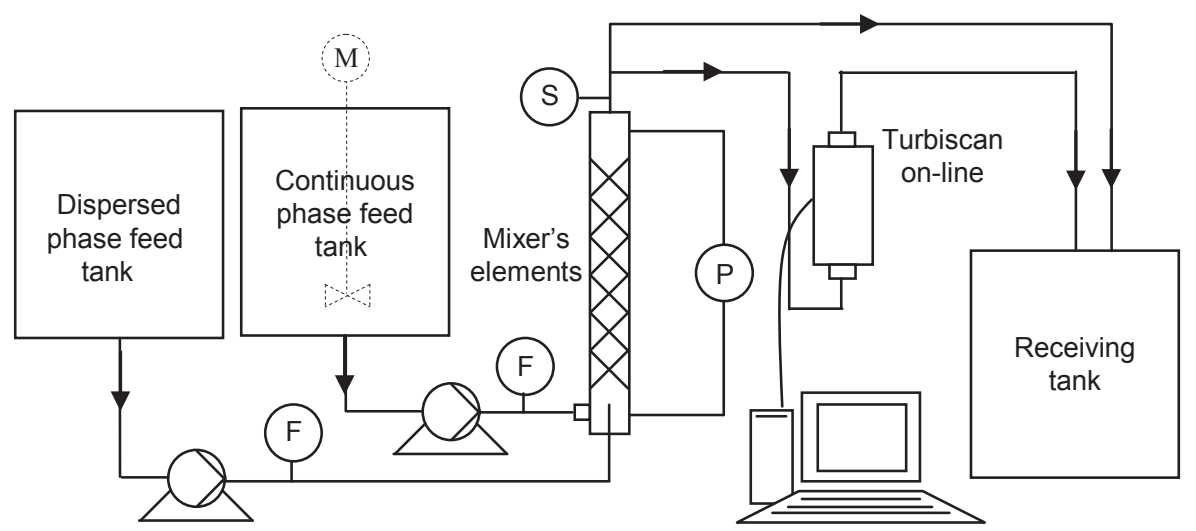

Fig. 2. Schematic diagram of the experimental rig: F, flowmeter; P: differential pressure sensor; and S: Sampling valve,

Table 4

Advantages and drawbacks of both droplets size analyses devices used.

\begin{tabular}{lll}
\hline & Advantages & Drawbacks \\
\hline Malvern Mastersizer 2000 & $\bullet$ Complete droplet size distribution: & • Sample dilution \\
& $d_{32}, d_{50}, d_{90}, d_{10} \ldots$ & $\bullet$ Sampling \\
On-Line Turbiscan & $\bullet$ On-line measurement & $\bullet$ Only $d_{32}$ \\
& $\bullet$ Non-destructive measurement \\
& $\bullet$ Concentrated system & \\
\hline
\end{tabular}

\subsection{Analytical aspects}

\subsubsection{Interfacial tension measurement}

The interfacial tension evolution with time is measured in the same range of the residence time in the mixer thanks to the Krüss DSA 100 tensiometer. The methodology and the raw data treatments are detailed by Lobry et al. (submitted for publication).

\subsubsection{Droplet size measurement}

The two analytical apparatuses used to measure mean droplet sizes and droplet size distributions are the Mastersizer 2000 (Malvern) for off-line analysis and the On-line Turbiscan (Formulaction) for on-line analysis. The Mastersizer 2000 principle is based on laser diffraction principle, and is frequently used for droplet size distributions analysis. The On-line Turbiscan is based on the principle of light backscattering. Its principle is described in the literature (Buron et al., 2004; Pizzino et al., 2009).

The different advantages and drawbacks of each technique are listed in Table 4. As they are based on different principles, these two methods give complementary results. For example, the use of the On-line Turbiscan allows to analyse on-line concentrated liquid-liquid dispersions, by a non-destructive measurement.

The Mastersizer 2000 provides more information about the distribution characteristics such as different characteristic diameters and distribution width, whereas the On-line Turbiscan only provides the $d_{32}$ value. They both give $d_{32}$ values, which enables them to be compared.

\section{Preliminary studies}

\subsection{Emulsions stability}

The four tested Water/Surfactant/Oil systems exhibit a creaming phenomenon. This phenomenon starts only few minutes after emulsification. If creaming is a reversible phenomenon, it may also be followed by some irreversible behaviour such as coalescence (Tadros and Vincent, 1983) or Ostwald ripening (Kalbanov et al., 1990; Yarranton and Masliyah, 1997).

Fig. 3 illustrates the comparison between droplets size distributions obtained through laser diffraction analysis several minutes after the experiment and about 24 hours after for the Water/Tween80/Cyclohexane system $\left(S_{1}\right)$ at $\Phi=0.25$ and the Water/PVA/Toluene system $\left(S_{3}\right)$ at $\Phi=0.50$. These distributions are almost superimposed which reveals that whatever the dispersed phase concentration no irreversible phenomenon occurs until $\Phi=0.50$. The same results are obtained for the two other systems at $\Phi=0.25$. As a conclusion the four systems investigated here are quite stable during at least 24 hours. The case of the system $S_{3}$ at $\Phi=0.60$ is described further.

\subsection{Droplets size analysis}

Fig. 4 is an optical microscopy picture of an emulsion sample obtained during an experiment involving the Water/PVA/Toluene system. Droplets are spherical and the diameters measured on the picture ranges from 10 to $120 \mu \mathrm{m}$.

Every laser diffraction analysis on all systems lead to similar droplet size distribution as the distribution presented in Fig. 3, which is monomodal in log-normal representation. Distributions are characterised through the mean diameters $d_{32}$ which is called the Sauter mean diameter defined by expression (4) and through the span which quantifies the width of the distribution (5)

$d_{32}=\frac{\sum_{i=1}^{n} n_{i} d_{i}^{3}}{\sum_{i=1}^{n} n_{i} d_{i}^{2}}$

where $n_{i}$ is the number of droplets which sizes range from $d_{i}$ to $d_{i+1}$

$\operatorname{span}=\frac{d_{90}-d_{10}}{d_{50}}$ 
a

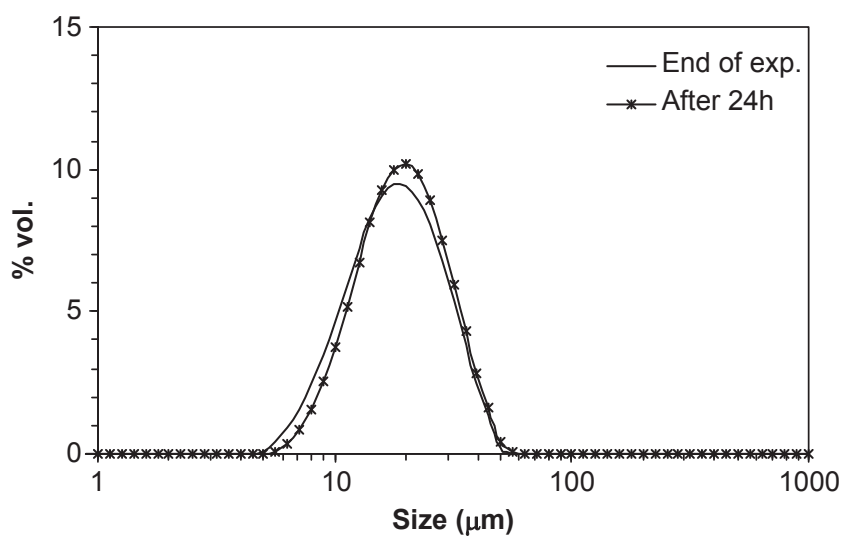

b

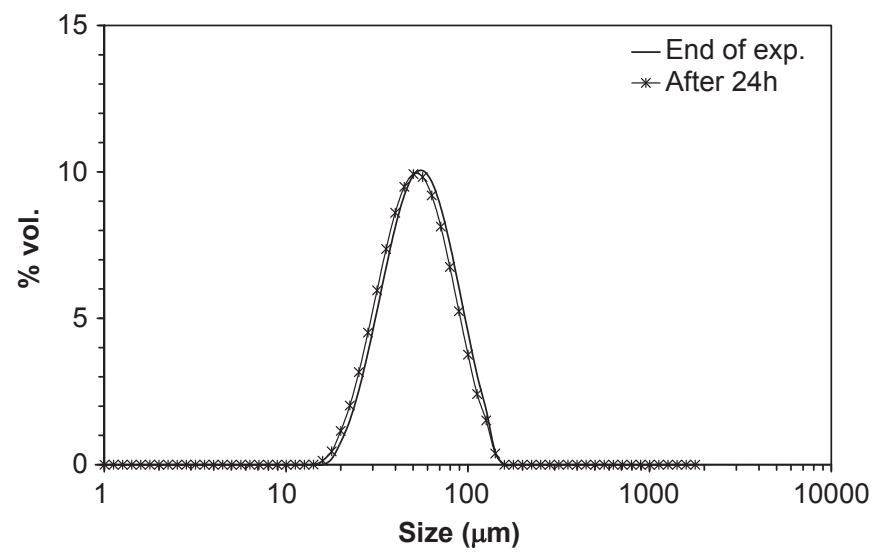

Fig. 3. Comparison between droplets size distributions obtained for the experiment carried out with (a) the Water/Tween80/Cyclohexane system $\left(S_{1}\right)$ at $Q_{\text {tot }}=500 \mathrm{~L} \mathrm{~h}^{-1}$ and $\Phi=0.25$ and with (b) the Water/PVA/Toluene system $\left(S_{3}\right)$ at $Q_{\text {tot }}=450 \mathrm{~L} \mathrm{~h}^{-1}$ and $\Phi=0.50$ just after the experiment and about 24 hours after the experiment.

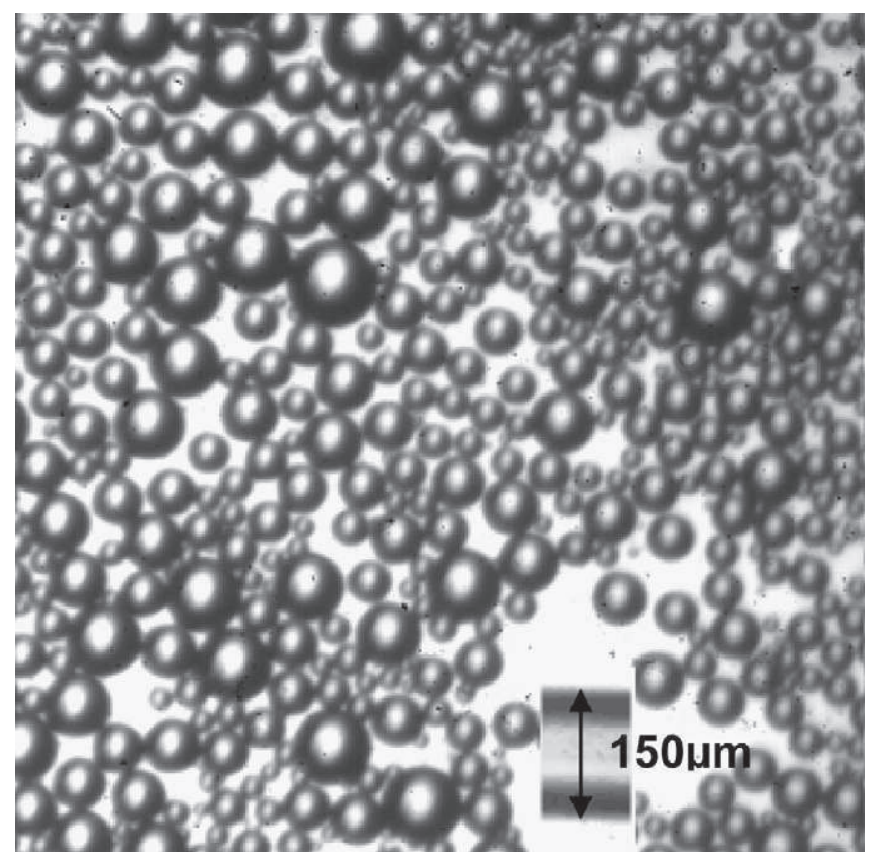

Fig. 4. Visualisation of droplets with the Nikon camera for the experiment carried out with the Water/PVA/Toluene system $\left(S_{3}\right)$ at $Q_{\text {tot }}=300 \mathrm{~L} \mathrm{~h}^{-1}$ and $\Phi=0.50$ $d_{32, \text { Malvern }}=59.0 \mu \mathrm{m}$
The $d_{90}$ which represents the highest diameter of $90 \%$ in volume of the dispersed phase is also used to characterise distributions.

$d_{10}$ represents the highest diameter of $10 \%$ in volume of the dispersed phase and $d_{50}$ is the median diameter of the distribution i.e. the highest diameter of $50 \%$ in volume of the dispersed phase. These two characteristic diameters are also directly obtained from the laser diffraction analysis.

3.3. Comparison between $d_{32}$ obtained with the Mastersizer 2000 (Malvern) and the On-line Turbiscan (formulation)

Fig. 5 compares $\mathrm{d}_{32}$ obtained with both analysis techniques for a total flowrate of $400 \mathrm{~L} \mathrm{~h}^{-1}$ and a dispersed phase concentration of 0.25 for all systems studied. The two different $d_{32}$ values are in quite good agreement for each system. In fact the discrepancy between both values ranges from 3\% to $15 \%$ whatever the system. The $d_{32}$ obtained from the On-line Turbiscan is either slightly higher or lower than the $d_{32}$ obtained by the off-line technique, which is why no special tendency can be highlighted.

Thus the use of the On-line Turbiscan allows to validate results obtained with the Mastersizer 2000 after sampling, dilution and latency time before analysis.

Both techniques are also compared for the Water/PVA/Toluene system at $400 \mathrm{~L} \mathrm{~h}^{-1}$ and three different dispersed phase concentrations (Fig. 6). The $d_{32}$ values are in the same range with a discrepancy ranging from $5 \%$ to $15 \%$.

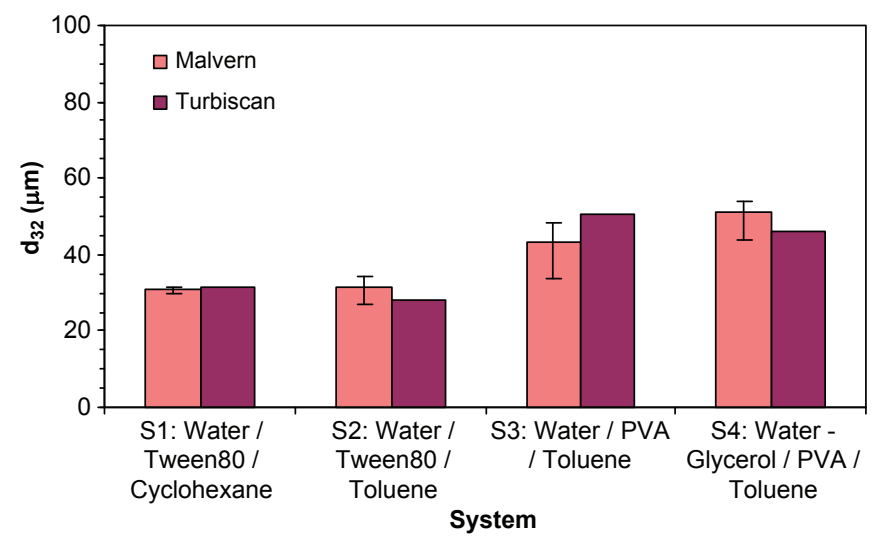

Fig. 5. Comparison between $d_{32}$ obtained with both Malvern and On-line Turbiscan for the four systems with $Q_{\text {tot }}=400 \mathrm{~L} \mathrm{~h}^{-1}$ and $\Phi=0.25$.

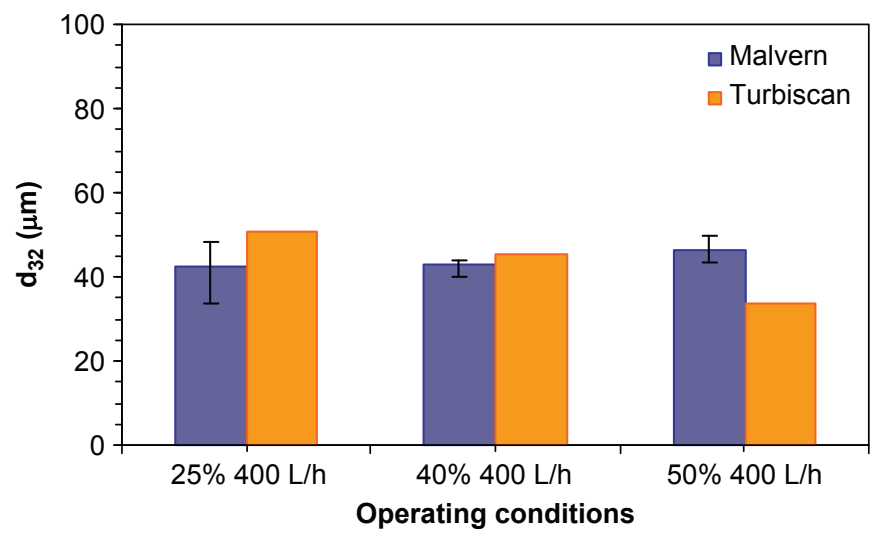

Fig. 6. Comparison between $d_{32}$ obtained with both Malvern and On-line Turbiscan for the Water/PVA/Toluene system $\left(S_{3}\right)$ for $Q_{\text {tot }}=400 \mathrm{~L} \mathrm{~h}^{-1}$ and different dispersed phase concentration $\Phi$. 
Whatever the system and the dispersed phase concentration $\Phi$, the $d_{32}$ calculated thanks to the On-line Turbiscan measurement are in good agreement with the values obtained from the laser diffraction technique. The main advantage of the Turbiscan is the ability to work directly on-line with high concentrated system. The maximum dispersed phase ratio depends on the studied system and generally cannot exceed 0.70 .

\section{Results and discussion}

The tested operating conditions and the residence time ranges in the static mixer $t_{R}$ are reported in Table 5 . The residence time $t_{R}$ is calculated thanks to the following equation:

$t_{R}=\frac{V_{\text {free for liquid flow }}}{Q_{\text {tot }}}=\frac{\varepsilon V_{\text {apparent of the mixer }}}{Q_{\text {tot }}}$

The residence time is calculated taking into account the free volume offered by the mixer to the flow, i.e. the void fraction of the mixer $(\varepsilon=0.83)$.

The influence of the dispersed phase concentration $\Phi$ on droplets size is studied in the range of $0.10-0.60$ in volume for the Water/PVA/Toluene system $\left(S_{3}\right)$. The four systems are compared at a fixed dispersed phase concentration $\Phi$, equal to 0.25 in volume. The systems $S_{1}$ and $S_{2}$, and the systems $S_{3}$ and $S_{4}$, respectively, enable the influence of the dispersed phase density and viscosity to be evaluated either by changing the dispersed phase or by modifying the continuous phase physical properties. From obtained results with the systems $S_{2}$ and $S_{3}$ the effect of the surfactant can be highlighted.

The energy cost of the operation only depends on the power required for pumping. To evaluate this parameter, the pressure drop is measured as noticed in the previous section (cf. Section 2.2). The pressure drop measurement allows to calculate the mean energy dissipation rate per fluid mass unit $\varepsilon_{m}$ as follows:

$\varepsilon_{m}=\frac{Q \Delta P}{V_{\text {free for liquid flow } \rho_{c}}}=\frac{Q \Delta P}{L \frac{\pi D^{2}}{4} \varepsilon \rho_{c}}$

\subsection{Pressure drop generated by the liquid-liquid flow through} the mixer

\subsubsection{Effect of the dispersed phase concentration on the pressure} drop-experimental results

Fig. 7 represents the evolution of the pressure drop as a function of the dispersed phase concentration for the Water/ PVA/Toluene system $\left(S_{3}\right)$ at four different flowrates. Whatever the flowrate the pressure drop exhibits the same behaviour: it

Table 5

Operating conditions for emulsification experiments.

\begin{tabular}{llll}
\hline System & $\begin{array}{l}\text { Dispersed phase } \\
\text { concentration } \Phi\end{array}$ & $\begin{array}{l}\text { Total flowrate } \\
\mathrm{Q}_{\text {tot }}\left(\mathrm{L} \mathrm{h}^{-1}\right)\end{array}$ & $\begin{array}{l}\text { Residence } \\
\text { time }(\mathrm{s})\end{array}$ \\
\hline $\begin{array}{l}S_{1}: \text { Water/Tween80/ } \\
\text { Cyclohexane }\end{array}$ & 0.25 & $274-550$ & $0.04-0.08$ \\
$\begin{array}{l}S_{2}: \text { Water/Tween80/ } \\
\text { Toluene }\end{array}$ & 0.25 & $274-552$ & $0.05-0.08$ \\
$S_{3}:$ Water/PVA/Toluene & 0.10 & & \\
& 0.25 & $273-553$ & $0.04-0.08$ \\
& 0.40 & $197-552$ & $0.04-0.11$ \\
& 0.50 & $202-550$ & $0.04-0.10$ \\
& 0.60 & $203-399$ & $0.05-0.10$ \\
$S_{4}:$ Water-Glycerol & 0.25 & $278-452$ & $0.04-0.08$ \\
$25 \% \mathrm{~m} /$ PVA/Toluene & & $274-553$ & $0.04-0.08$ \\
\end{tabular}

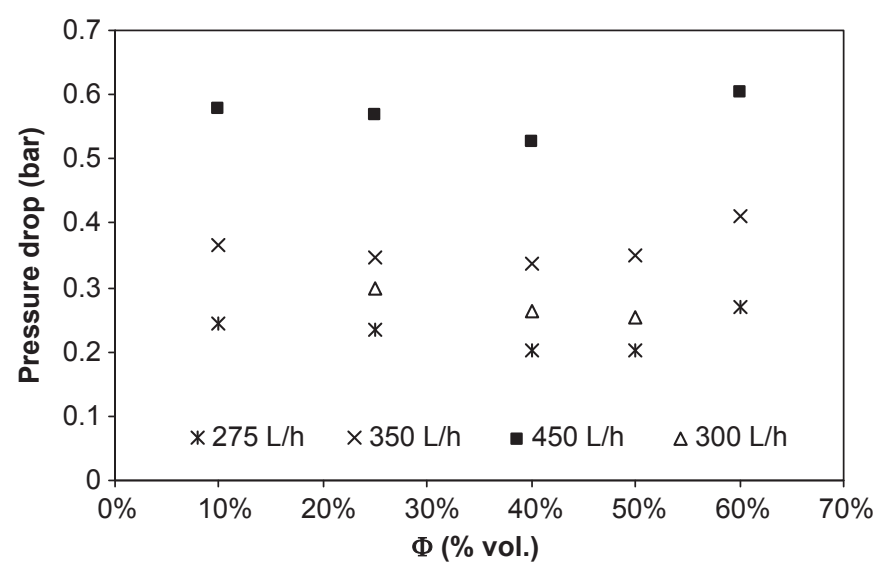

Fig. 7. Evolution of the pressure drop with the dispersed phase concentration $\Phi(\% \mathrm{vol})$ at different flowrates for the Water/PVA/Toluene system $\left(S_{3}\right)$.

decreases from $\Phi=0.10$ to $\Phi=0.50$ and raises suddenly at a concentration close to $0.50-0.60$. Moreover, the observation of the sampling after creaming allows to identify three phases for the emulsion obtained at 0.60 ; some aqueous phase at the bottom, some emulsion in the middle and some toluene at the top. We thus assume that the obtained system is not the expected oil-in-water emulsion and tends to be more complex, like perhaps multiple emulsions.

The pressure drop increase between $\Phi=0.50$ and $\Phi=0.60$ may be due to a phase inversion phenomenon. The same pressure drop evolution has already been reported in the literature in empty pipes for two phases flow without surfactant (Ioannou et al., 2005; De et al., 2010). The authors studied the phase inversion phenomenon by acting on the dispersed phase ratio at constant flowrate. As observed in the present study the pressure drop slightly decreases when increasing the oil fraction $(\Phi=0.20-$ 0.50 ), and then significantly increases over a small range of dispersed phase concentration $(\Phi=0.50-0.65)$. This sudden increase of the pressure drop appears just before the phase inversion phenomenon. Then the pressure drop decreases suddenly when the phase inversion phenomenon occurs. Finally the pressure drop increases gradually up to the single phase oil value.

Phase inversion in motionless mixers has been studied by Tidhar et al. (1986) in stainless steel or Teflon SMV mixers, made of four elements. They worked with water/kerosene, water/ carbon tetrachloride $\left(\mathrm{CCl}_{4}\right)$ and water/kerosene $+\mathrm{CCl}_{4}$ systems, without surfactant. They noticed that whatever the mixer material, phase inversion at high flowrate occurs around $\Phi=0.50$.

According to our observations and literature comparisons it can be assumed that at $\Phi=0.60$ the phase inversion point is almost reached. Additional studies would be interesting to complete these results.

\subsubsection{Modelling of the pressure drop in two phase flow}

The pressure drop generated by single-phase flow in static mixers has been widely studied and modelled. But it is not as well documented concerning two-phase flows. In fact physical properties of such complex systems and especially the viscosity are not easily assessable. Numerous references can be found concerning the pressure drop generated by gas-liquid dispersions in static mixers: Shah and Kale (1991, 1992a, 1992b) and Chandra and Kale (1995) for the Kenics, Sulzer SMX and Komax static mixers, Streiff (1977) for Sulzer static mixers; Turunen (1994) for SMV static mixer; and Heyouni et al. (2002) for the Lightnin mixer. However liquid-liquid dispersions are not much examined. 
For liquid-liquid flows, "mixing" physical properties (density and viscosity) of the system must be defined. Legrand et al. (2001) have studied pressure drops in SMX static mixer by assuming the static mixer as a porous media. They use the "mixing" density as defined in the present paper and choose a viscosity model (Taylor, $1935)$ to calculate an apparent viscosity.

Different dimensionless numbers can be encountered to represent the pressure drop generated by motionless mixers in the open literature. Lemenand et al. (2005) who have investigated the HEV static mixer define a $Z$ factor corresponding to the pressure drop ratio between the emulsion flow in static mixer (HEV) and a single phase flow in a simple duct. They reported $Z$ factors ranging from 2 to 8 for dispersed phase concentration ranging from 0 to 0.15 in volume, with a decreasing tendency when increasing the dispersed phase concentration.

In the same way, the pressure drop generated by the liquidliquid flow in the SMV mixer used in this study $\Delta P_{\text {liq-liq,SM }}$ is compared to the pressure drop generated in single phase flow by the continuous phase in an empty pipe $\Delta P_{\text {mono,EP }}$ through a $Z$ factor as follows:

$Z=\frac{\Delta P_{\text {liq-liq,SM }}}{\Delta P_{\text {mono,EP }}}$

where the $\Delta P_{\text {mono,EP }}$ value is calculated thanks to the Blasius equation.

The $Z$ values obtained, respectively, for the system $S_{3}$ at different $\Phi$ values and for the four systems at $\Phi=0.25$ are recapitulated in Tables 6 and 7 .

The $Z$ factors obtained in the present study are in the order of about 120 . This is much higher than the values reported by

Table 6

$Z$ factor for the system $S_{3}$.

\begin{tabular}{lllllll}
\hline$\Phi$ & 0.10 & 0.20 & 0.25 & 0.40 & 0.50 & 0.60 \\
$Z$ & 122 & 120 & 118 & 117 & 113 & 132 \\
\hline
\end{tabular}

Table 7

$Z$ factor for the different systems at $\Phi=0.25$.

\begin{tabular}{lllll}
\hline System & $\begin{array}{l}S_{1}: \text { Water/ } \\
\text { Tween80/ } \\
\text { Cyclohexane }\end{array}$ & $\begin{array}{l}S_{2}: \text { Water/ } \\
\text { Tween80/ } \\
\text { Toluene }\end{array}$ & $\begin{array}{l}S_{3}: \text { Water } / \\
\text { PVA } / \\
\text { Toluene }\end{array}$ & $\begin{array}{l}S_{4}: \text { Water-Glycerol } \\
25 \% \mathrm{~m} / \text { PVA/Toluene }\end{array}$ \\
\hline$Z$ & 107 & 115 & 118 & 132 \\
\hline
\end{tabular}

Lemenand et al. (2005). This may be due to the more open design of the HEV mixer that they used.

Another way of representing the pressure drop is the Fanning friction factor $f$ or the Newton number only valid for Newtonian fluids (Shah and Kale, 1991, 1992a, 1992b; Streiff et al., 1997). This friction factor or Newton number is correlated to the Reynolds number.

In this study, the pressure drop is expressed in terms of friction factor $f$ taking into account the geometric parameters of the system: the porosity of the mixer $\varepsilon$ and the hydraulic diameter of the static mixer $d_{h}$

$f_{h}=\frac{\Delta P \varepsilon^{2}}{2 \rho V_{0}^{2}} \frac{d_{h}}{L}$

In Eq. (8), $V_{0}$ is the flow velocity. The ratio $V_{0} / \varepsilon$ is generally called "interstitial velocity", and is used to characterise velocity in porous media.

This friction factor is related to the hydraulic Reynolds number (9)

$\operatorname{Re}_{h}=\frac{\rho_{e} V_{0} d_{h}}{\varepsilon \mu}$

where the density is the equivalent density defined previously (cf. Section 2.1) and the viscosity is the continuous phase viscosity.

Figs. 8 and 9, respectively, illustrate the evolution of the hydraulic Fanning friction factor $f_{h}$ as a function of the hydraulic Reynolds number $\operatorname{Re}_{h}$ in the case of the Water/PVA/Toluene system $\left(S_{3}\right)$ with different dispersed phase ratio and for the four systems at $\Phi=0.25$. The Fanning friction factors $f_{h}$ is well represented towards the hydraulic Reynolds number by a power law.

The obtained result is similar to the result exhibited in single phase flow by Bohnet et al. (1990) and Li et al. (1997). The -0.25 value of the Reynolds number exponent corresponds to the value found in the Blasius correlation established for turbulent flow in empty pipe.

This result indicates that the obtained emulsions apparent viscosity can fairly be represented by the continuous phase one even if the rheological behaviours of the systems investigated are more complex.

4.2. Effect of physico-chemical parameters on $d_{32}$ : $\Phi$, surfactant, $\mu_{d} / \mu_{c}$ and $\rho_{d} / \rho_{c}$

\subsubsection{Effect of $\Phi$}

The effect of $\Phi$ on the droplet size distribution is studied for the Water/PVA/Toluene system $\left(S_{3}\right)$, for given operating conditions. Droplet size distributions obtained at different dispersed phase

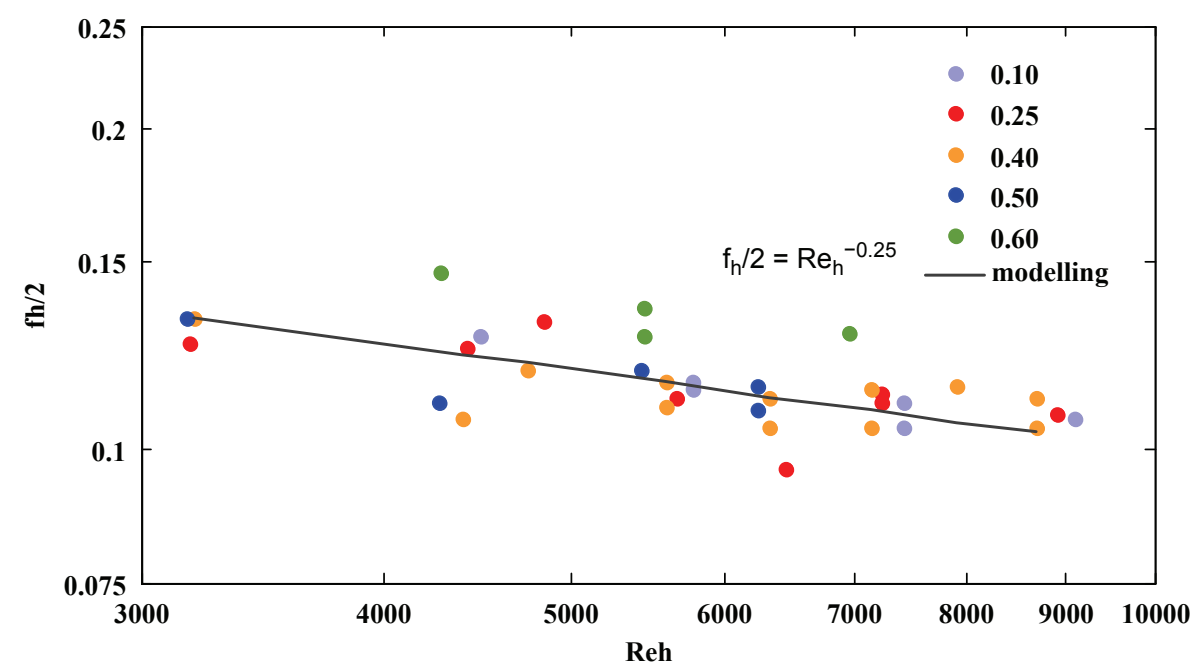

Fig. 8. Correlation of experimental results for the Water/PVA/Toluene system $\left(S_{3}\right)$ at different dispersed phase concentration $\Phi$ in volume. 


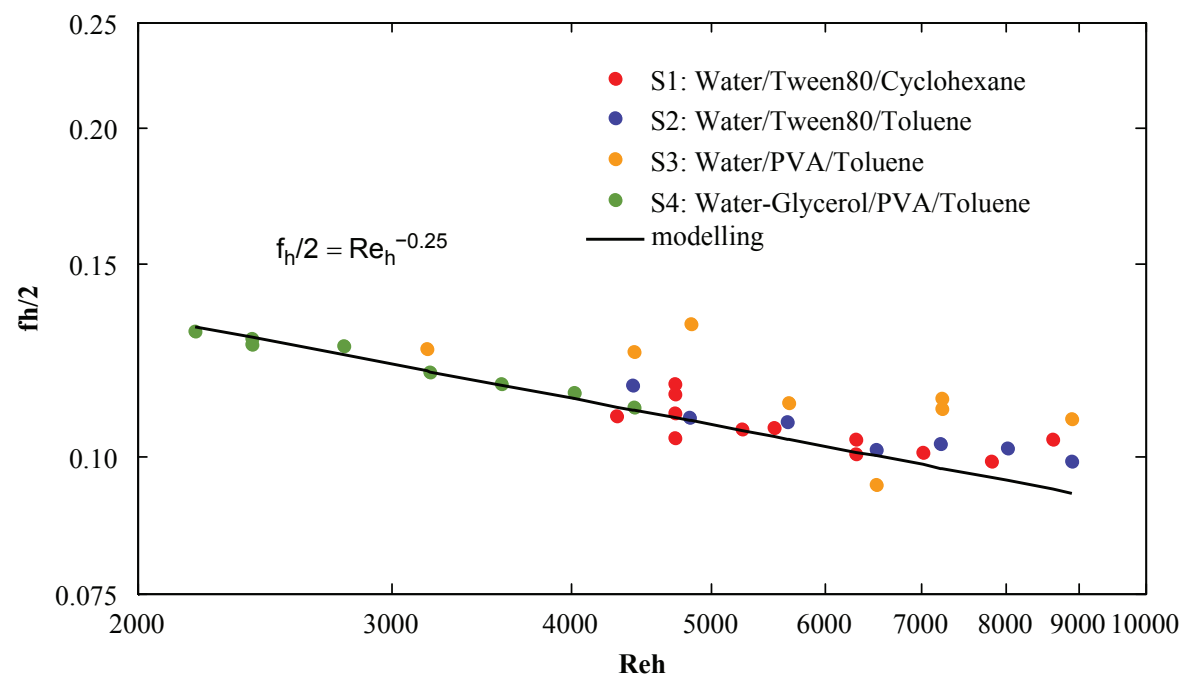

Fig. 9. Correlation of experimental results for the four systems tested at $\Phi=0.25$.

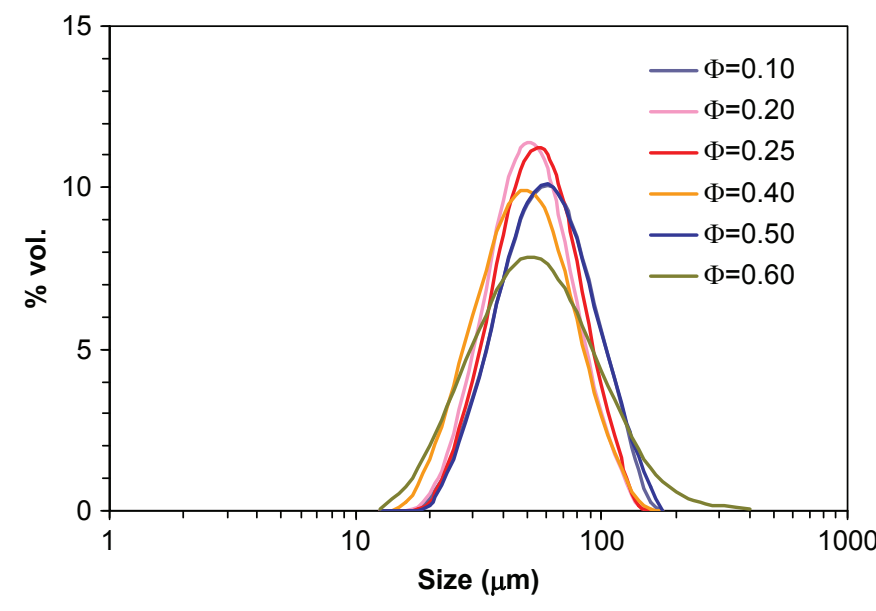

Fig. 10. Comparison between droplets size distributions obtained with different dispersed phase concentration $\Phi$ for the Water/PVA/Toluene $\left(S_{3}\right)$ system for $Q_{\text {tot }}=350 \mathrm{~L} \mathrm{~h}^{-1}$ (see Table 8).

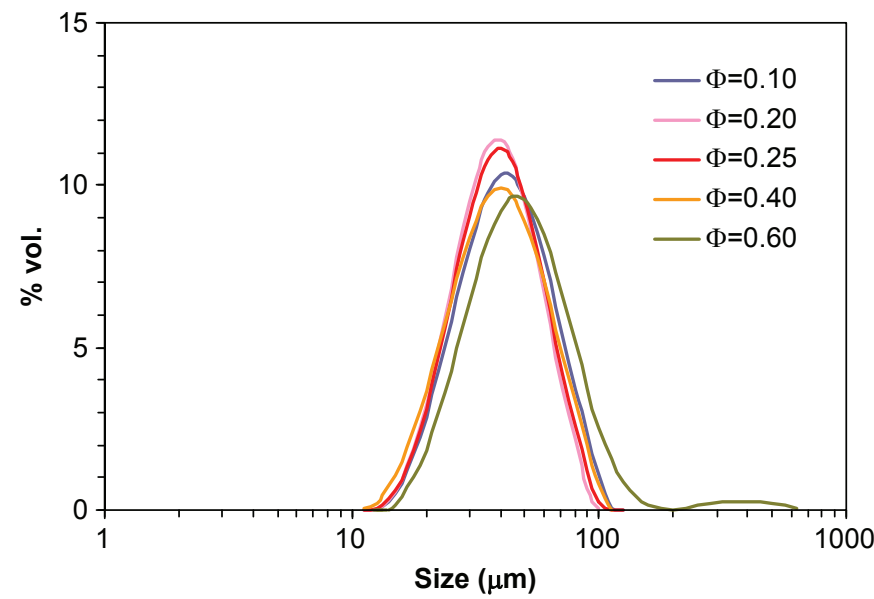

Fig. 11. Comparison between the droplets size distributions obtained at different dispersed phase concentration $\Phi$ for the Water/PVA/Toluene system $\left(S_{3}\right)$ for $Q_{\text {tot }}=450 \mathrm{~L} \mathrm{~h}^{-1}$ (see Table 9).

concentrations for two different flowrates are presented in Figs. 10 and 11. Tables 8 and 9 give the $d_{32}$ and the span values characterising these distributions.
Table 8

$d_{32}$ and span obtained for the different dispersed phase ratio for the Water/PVA/ Toluene system $\left(S_{3}\right)$ for $Q_{\text {tot }}=350 \mathrm{~L} \mathrm{~h}^{-1}$.

\begin{tabular}{lcccccc}
\hline$\Phi$ & 0.10 & 0.20 & 0.25 & 0.40 & 0.50 & 0.60 \\
$d_{32} \mu \mathrm{m}$ & 61.8 & 52.3 & 54.4 & 46.7 & 59.6 & 55.5 \\
span & 1.1 & 1.2 & 1.1 & 1.2 & 1.2 & 1.9 \\
\hline
\end{tabular}

Table 9

$d_{32}$ and span obtained for the different dispersed phase ratio for the Water/PVA/ Toluene system $\left(S_{3}\right)$ for $Q_{\text {tot }}=450 \mathrm{~L} \mathrm{~h}^{-1}$.

\begin{tabular}{lccccc}
$\Phi$ & 0.10 & 0.20 & 0.25 & 0.40 & 0.60 \\
$d_{32} \mu \mathrm{m}$ & 38.9 & 37.1 & 38.3 & 37.12 & 40.1 \\
span & 1.1 & 1.1 & 1.2 & 1.2 & 2.1 \\
\hline
\end{tabular}

The droplet size distributions are totally superimposed whatever the dispersed phase ratio except for $\Phi=0.60$. Same result is obtained whatever the total flowrate, $Q_{\text {tot }}$. For given operating conditions the $d_{32}$ are in the same range whatever $\Phi$ (cf. Tables 8 and 9). Only the span exhibits a significant increase at $\Phi=0.60$. The dispersed phase concentration thus seems to have little influence on the distribution obtained except at a 0.60 dispersed phase ratio. It is interesting to notice that the droplet size distribution change in tendency is observed for $\Phi$ equal to 0.60 , as well as the pressure drop increase described in Section 4.1.1.

These results are totally different from results generally observed in stirred tank where an increase of the dispersed phase volume fraction leads to larger droplet size (Desnoyer et al., 2003; Angle et al., 2006; Angle and Hamza, 2006) even when surfactants are involved.

It seems that no coalescence occurs and that liquid-liquid dispersion in static mixers is only controlled by the breakage mechanism. In order to justify this hypothesis, the characteristic times of the process, i.e. the residence time and the coalescence time are compared.

The flow type must first be identified. So Kolmogoroff's length scale $\eta$ is calculated thanks to the following expression:

$\eta=\left(\frac{v_{c}^{3}}{\varepsilon_{m}}\right)^{1 / 4}$

where $v_{c}$ is the kinematic viscosity of the continuous phase and $\varepsilon_{m}$ is the mean energy dissipation rate per fluid mass unit. 
Table 10 gives Kolmogoroff's length scale for the four systems. Given that $\eta_{K}<d_{32}<d_{h}$ the turbulent regime that takes place in the static mixers studied is of inertial type.

The coalescence efficiency $P$ is defined by the following formula (Coulaloglou, 1975):

$P=\exp \left(-\frac{t_{\text {drainage }}}{t_{\text {contact }}}\right)$

For a non-deformable rigid sphere, the contact time $t_{\text {contact }}$ is estimated by the following expression (Levich, 1962) in turbulent systems:

$t_{\mathrm{contact}} \approx \frac{d^{2 / 3}}{\varepsilon_{m}^{1 / 3}}$

The drainage time is estimated by integrating the model corresponding to the rigid drop of Chesters (1991) which gives the interaction force $F$

$F=\frac{3 \pi \mu_{C} R^{2}}{2 h}\left(-\frac{d h}{d t}\right)$

where $R$ is the radius of a droplet and $h$ represents the film thickness between two droplets.

For $F$ constant, $h$ is defined as follows:

$h=h_{0} \exp \left(-\frac{t}{t_{c h}}\right)$

where $t_{c h}$ is the characteristic time defined by

$t_{c h}=\frac{3 \pi \mu_{C}}{2 F}$

The drainage time corresponds to the time at which the critical thickness $h_{c}$ is reached.

$h_{c}$ is given by

$h_{c} \approx\left(\frac{A R}{8 \pi \sigma}\right)^{1 / 3}$

where $A$ is the Hamacker constant taken equal to $10^{-20} \mathrm{~J}$.

Consequently $t_{\mathrm{drainage}}$ is calculated by integrating the expression (14) with $h=h_{c}$ and $t=t_{\text {drainage. }}$

Table 11 sums up the different ranges of the calculated values for each system.

The drainage time is always higher than the contact time Consequently, the coalescence probability is very low.

The dispersed phase concentration seems to have no influence as long as the oil phase is totally dispersed as droplets in the continuous phase. More experiments will be useful to precisely

Table 10

Kolmogoroff's length scale for the four systems.

\begin{tabular}{ll}
\hline System & Kolmogoroff's length scale $\eta(\mu \mathrm{m})$ \\
\hline$S_{1}:$ Water/Tween80/Cyclohexane & $5-8$ \\
$S_{2}:$ Water/Tween80/Toluene & $5-8$ \\
$S_{3}:$ Water/PVA/Toluene & $5-7$ \\
$S_{4}:$ Water-Glycerol 25\%m/PVA/Toluene & $8-12$ \\
\hline
\end{tabular}

determine if a phase inversion phenomenon occurs for higher dispersed phase concentration than 0.50 . In the following calculations and correlations data obtained at $\Phi=0.60$ are not included.

\subsubsection{Effect of surfactant, $\mu_{d} / \mu_{c}$ and $\rho_{d} / \rho_{c}$}

Fig. 12 illustrates the influence of surfactant, viscosity and density ratio through the four different investigated systems on droplet size distributions obtained at the same dispersed concentration $(\Phi=0.25)$ and total flowrate $\left(Q_{\text {tot }}=300 \mathrm{~L} \mathrm{~h}^{-1}\right)$. Sauter mean diameters as well as span characterizing these distributions are recapitulated in Table 12 .

Fig. 12 shows that whatever the continuous phase and dispersed phase, droplet sizes are smaller when the Tween 80 surfactant is involved. Distributions obtained with PVA as the surfactant present higher minimum and maximum diameters than distributions obtained with Tween80. The distribution obtained with Water-Glycerol (25\% mass) as the continuous phase is slightly shifted to larger sizes compared to the distribution obtained without glycerol.

The only difference between systems $S_{2}$ and $S_{3}$ is the surfactant. This result indicates that the interfacial tension between continuous and dispersed phase plays an important role in the break-up phenomenon. For emulsification operations in classical stirred tanks for example, the interfacial tension value considered is the value at equilibrium. The interfacial tension at equilibrium for each system is reported in Table 13. From Table 13 it appears

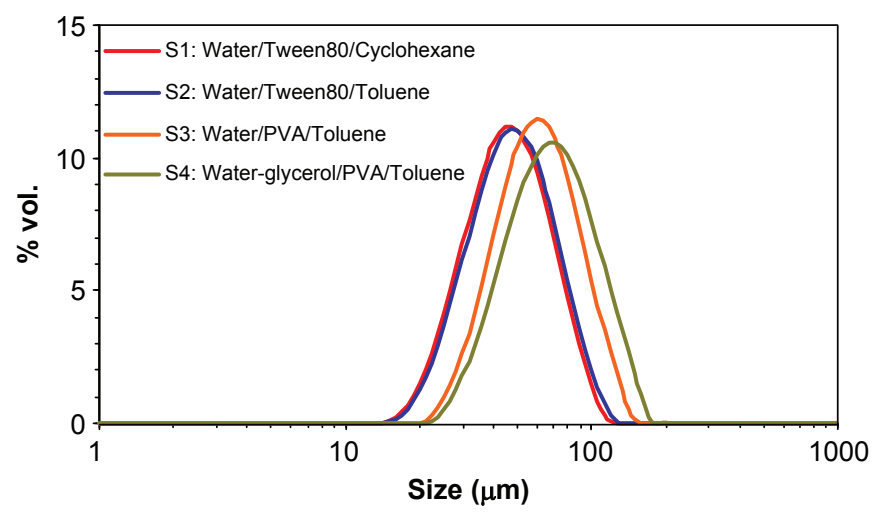

Fig. 12. Comparison between droplets size distributions obtained with the four systems tested at $\Phi=0.25$ and $Q_{\text {tot }}=300 \mathrm{~L} \mathrm{~h}^{-1}$ (see Table 10 ).

Table 12

$d_{32}$ and SPAN obtained for the four systems from experiments carried out at $Q_{\text {tot }}=300 \mathrm{~L} \mathrm{~h}^{-1}$ and $\Phi=0.25$.

\begin{tabular}{lllll}
\hline System & $\begin{array}{l}S_{1}: \text { Water/ } \\
\text { Tween80/ } \\
\text { Cyclohexane }\end{array}$ & $\begin{array}{l}S_{2}: \text { Water/ } \\
\text { Tween80/ } \\
\text { Toluene }\end{array}$ & $\begin{array}{l}S_{3}: \text { Water/ } \\
\text { PVA/ } \\
\text { Toluene }\end{array}$ & $\begin{array}{l}S_{4}: \text { Water-Glycerol } \\
(25 \% \mathrm{~m}) / \mathrm{PVA} / \\
\text { Toluene }\end{array}$ \\
\hline$d_{32}(\mu \mathrm{m})$ & 45.0 & 46.9 & 59.8 & 72.1 \\
Span & 1.1 & 1.1 & 1.0 & 1.2 \\
\hline
\end{tabular}

Table 11

Comparison of different characteristic time of the liquid-liquid dispersion.

\begin{tabular}{|c|c|c|c|c|c|c|}
\hline System & $\begin{array}{l}\text { Residence } \\
\text { time (s) }\end{array}$ & $\begin{array}{l}\text { Characteristic } \\
\text { time } t_{c h}(\mathrm{~s})\end{array}$ & $\begin{array}{l}\text { Contact time } \\
t_{\text {contact }}(\mathrm{s})\end{array}$ & $\begin{array}{l}\text { Drainage time } \\
t_{\text {drainage }}(\mathrm{s})\end{array}$ & $\frac{t_{\text {drainage }}}{t_{\text {contact }}}$ & $P$ \\
\hline$S_{1}$ : Water/Tween80/Cyclohexane & $0.04-0.08$ & $1.8 .10^{-4}-3.10^{-4}$ & $4.9 .10^{-5}-2.3 .10^{-4}$ & $1.2 .10^{-3}-2.2 .10^{-3}$ & $9.7-23.9$ & 4.3.10 $10^{-11}-6.2 .10^{-5}$ \\
\hline$S_{2}:$ Water/Tween80/Toluene & $0.04-0.08$ & $1.7 .10^{-4}-3.2 .10^{-4}$ & $5.10^{-5}-2.1 .10^{-4}$ & $1.2 .10^{-3}-2.3 .10^{-3}$ & $11.2-23.8$ & 4.5.10 $10^{-11}-1.4 .10^{-5}$ \\
\hline$S_{3}:$ Water/PVA/Toluene & $0.04-0.11$ & $1.1 .10^{-4}-3.1 .10^{-4}$ & $7.5 .10^{-5}-5.1 .10^{-4}$ & $8.0 .10^{-4}-2.5 .10^{-3}$ & $4.9-10.6$ & $2.4 .10^{-5}-7.9 .10^{-3}$ \\
\hline$S_{4}$ : Water-Glycerol $(25 \% \mathrm{~m}) / \mathrm{PVA} /$ Toluene & $0.04-0.08$ & $9.6-10^{-5}-2.2 .10^{-4}$ & $8.10^{-5}-2.5 .10^{-4}$ & $6.9 .10^{-4}-1.7 .10^{-3}$ & $6.1-8.6$ & 4.5.10 $10^{-11}-1.4 .10^{-5}$ \\
\hline
\end{tabular}


that the discrepancy between interfacial tension values at equilibrium of systems $S_{2}$ and $S_{3}$ is too low to explain the discrepancy between distributions obtained for these systems.

For both systems the surfactant concentration is higher than the Critical Micellar Concentration (CMC). The break-up phenomenon in static mixer occurs during a very short time $\left(t_{r}=0.04-0.11 \mathrm{~s}\right)$. The interfacial tension value between both phases after the emulsification is thus not equal to the value at equilibrium. So the interfacial tension between both phases depends on the short time surfactant adsorption kinetics, which depends on the surfactant properties. The interfacial tension values at half the residence time in the mixer $\sigma_{m}$, i.e. the apparent interfacial tension values for the operation considered, are reported in Table 13 for each system at $Q_{\text {tot }}=300 \mathrm{Lh}^{-1}$. The methodology developed to acquire transient interfacial tension values is detailed by Lobry et al. (submitted for publication).

The interfacial tension at equilibrium reached with the PVA surfactant $\left(S_{3}\right)$ is lower than the value reached with the Tween 80 surfactant $\left(S_{2}\right)$. However the $\sigma_{m}$ value at times of the same order as half the residence time in the mixer is lower for the Water/

\section{Table 13}

Interfacial tension values without surfactant, at equilibrium, and at half the residence time in the mixer for $Q_{\text {tot }}=300 \mathrm{~L} \mathrm{~h}^{-1}\left(t_{r} / 2=0.03 \mathrm{~s}\right)$ for the four systems.

\begin{tabular}{llll}
\hline System & $\begin{array}{l}\sigma_{\text {without surfactant }} \\
\left(\mathrm{mN} \mathrm{m}^{-1}\right)\end{array}$ & $\begin{array}{l}\sigma_{e q} \\
\left(\mathrm{mN} \mathrm{m}^{-1}\right)\end{array}$ & $\begin{array}{l}\sigma_{m} \\
\left(\mathrm{mN} \mathrm{m}^{-1}\right)\end{array}$ \\
\hline$S_{1}:$ Water/Tween80/ & 47.0 & 3.0 & 14.3 \\
$\quad$ Cyclohexane & & & \\
$S_{2}:$ Water/Tween80/Toluene & 36.0 & 7.0 & 13.8 \\
$S_{3}:$ Water/PVA/Toluene & 36.0 & 3.5 & 25.8 \\
$S_{4}:$ Water-Glycerol (25\%m)/ & 30.0 & 4.7 & 25.7 \\
$\quad$ PVA/Toluene & & & \\
\hline
\end{tabular}

Tween80/Toluene system $\left(S_{2}\right)$ compared to the value for the Water/PVA/Toluene system $\left(S_{3}\right)$. This may be explained by the higher molecular weight of the PVA that results in slower diffusion times, whereas lower interfacial tension values at equilibrium due to higher sterical crowding are reached with PVA.

The slight discrepancy between both distributions obtained with Tween 80 (systems $S_{1}$ and $S_{2}$ ) may be explained by the measurement precision. For the two systems involving PVA (systems $S_{3}$ and $S_{4}$ ), the discrepancy is more important, and may thus be explained by the difference between viscosity and density ratio. In fact, a decrease of both the $\rho_{d} / \rho_{c} \mu_{d} / \mu_{c}$ ratio results in an increase of the maximum diameter, and thus in an increase of the $d_{32}$ and the span values.

\subsection{Modelling of experimental results}

\subsubsection{Prediction of mean diameters: existing correlations}

If there are many correlations in the literature that predict mean diameters resulting from emulsification in static mixers, only few of them have been established for the SMV mixer (cf. Table 14). Most of these correlations are based on Kolmogoroff's theory of turbulence. This theory assumes a homogeneous and isotropic turbulence flow field and enables the prediction of the maximum stable droplets size as follows:

$d_{\max }=K\left(\frac{\sigma}{\rho_{c}}\right)^{0.6} \varepsilon_{m}^{-0.4}$

Kolmogoroff's theory of turbulence was first proposed to predict mean droplets size obtained in Kenics mixers by Middleman (1974). From this expression he established a correlation defined

Table 14

Model found in the literature to correlate the mean droplet diameter to different parameters (hydrodynamic, physical and dimensionless parameters).

\begin{tabular}{|c|c|c|c|c|}
\hline Authors & Static mixer design & $\begin{array}{l}\text { Characteristic } \\
\text { diameter }\end{array}$ & Correlation & Flow regime \\
\hline Middleman (1974) & Kenics & $D$ & $\frac{d_{32}}{D}=K \mathrm{We}^{-0.6} \mathrm{Re}^{0.1}$ & Turbulent \\
\hline Streiff (1977) & SMV & $D_{h}$ & $\frac{d_{32}}{D_{h}}=0.21 \mathrm{We}_{h}{ }^{-0.5} \mathrm{Re}_{h}{ }^{0.15}$ & Transient, turbulent \\
\hline Chen and Libby (1978) & Kenics & $D$ & $\frac{d_{32}}{D}=1.14 \mathrm{We}^{-0.75}\left(\frac{\mu_{d}}{\mu_{c}}\right)^{0.18}$ & Turbulent \\
\hline Matsumura et al. (1981) & Hi-mixer & $D$ & $\frac{d_{32}}{D}=K \mathrm{We}_{c}^{-n} n=0.56-0.67$ & Turbulent \\
\hline Al Taweel and Walker (1983) & Lightnin & $D_{h}$ & $\frac{d_{32}}{D_{h}}=K \mathrm{We}^{-0.6} f^{-0.4}$ & Turbulent \\
\hline Haas (1987) & Kenics & $D$ & $\frac{d_{43}}{D}=1.2 \mathrm{We}^{-0.65} \mathrm{Re}^{-0.2}\left(\frac{\mu_{d}}{\mu_{c}}\right)^{0.5} 0$ & Laminar \\
\hline Berkman and Calabrese (1988) & Kenics & $D$ & $\frac{d_{32}}{D}=0.49 \mathrm{We}^{-0.6}\left(1+1.38 \mathrm{~V}\left(\frac{d_{32}}{D}\right)^{0.33}\right)^{0.6}$ & Turbulent \\
\hline Al Taweel and Chen (1996) & Woven screen & & $d_{32}=0.682\left(\mathrm{We}_{j e t}^{-0.859} \varphi^{0.875}\right)\left(\frac{b}{M}\right)^{0.833}$ & Turbulent \\
\hline Streiff et al. (1997) & SMV, SMX, SMXL & & $d=C_{n}(1+K \varphi)\left(\frac{(1+B V i) \mathrm{We}_{c}}{2}\right)^{0.6}\left(\frac{\sigma}{\rho_{c}}\right)^{0.6}\left(\frac{\rho_{c}}{\rho_{d}}\right)^{0.1} \varepsilon^{-0.4}$ & \\
\hline & & & $d_{\max }=0.94\left(\frac{\sigma}{\rho_{c}}\right)^{0.6} \varepsilon^{-0.4}$ & \\
\hline Legrand et al. (2001) & SMX & $d_{p}$ & $\frac{d_{32}}{d_{p}}=0.29 \mathrm{We}_{p}{ }^{-0.2} \operatorname{Re}_{p}{ }^{-0.16}$ & Laminar, transient and turbulent \\
\hline Lemenand et al. (2001, 2003, 2005) & HEV & $D$ & $\frac{d_{32}}{D}=0.57 \mathrm{We}^{-0.6}$ & Turbulent \\
\hline Das et al. (2005) & SMX & $d_{p}$ & $\frac{d_{\max }}{d_{p}}=C \mathrm{We}_{p}^{-0.33}$ & Laminar, transient \\
\hline Rama Rao et al. (2007) & SMX & $D$ & $\frac{d_{43}}{D}=K\left(1.5 \varphi\left(1+\frac{\mu_{d}}{\mu_{c}}\right)\right)^{0.5}$ & Laminar \\
\hline Hirschberg et al. (2009) & SMX plus & & $d=C_{n}(1+K \varphi)\left(\frac{(1+B V i) W e_{c}}{2}\right)^{0.6}\left(\frac{\sigma}{\rho_{c}}\right)^{0.6}\left(\frac{\rho_{c}}{\rho_{d}}\right)^{0.1} \varepsilon^{-0.4}$ & Turbulent \\
\hline
\end{tabular}


as a function of dimensionless numbers

$\frac{d_{32}}{D}=K \mathrm{We}^{-0.6} f^{-0.4}$

where We is the Weber number that represents the ratio of turbulent pressure fluctuations tending to deform and break up the drop and the interfacial tension resisting to this deformation defined as follows:

$\mathrm{We}=\frac{\rho V_{0} D}{\sigma}$

Assuming a Blasius like dependency of the friction factor towards the Reynolds number (cf. Section 4.1.2) Eq. (18) can be expressed in terms of Weber and Reynolds numbers

$\frac{d_{32}}{D}=K \mathrm{We}^{-0.6} \mathrm{Re}^{0.1}$

After Middleman (1974), many authors proposed correlations based on Kolmogoroff's turbulence theory to predict mean diameters.

Correlations recapitulated in Table 12 show that the Weber number is the main parameter involved in the break-up phenomenon in static mixers. Some authors (Chen and Libby, 1978; Haas, 1987; Streiff et al., 1997; Rama Rao et al., 2007; Hirschberg et al., 2009) also reported the influence of physico-chemical parameters on the operation through densities or viscosities ratio.

If most of correlations enable the prediction of $d_{32}$ values, some authors established expressions to estimate $d_{43}$ or $d_{\max }$ values. For liquid-liquid dispersions the $d_{32}$ values are preferred as they are easier to determine experimentally and they are usually employed for example for mass transfer issues. In fact it is possible from $d_{32}$ values to calculate the interfacial area $A$ $\left(\mathrm{m}^{2} \mathrm{~m}^{-3}\right)$ developed by the dispersed phase as follows:

$d_{32}=\frac{6 \phi}{A}$

\subsubsection{Relationship between $d_{32}$ and $d_{90}$}

The proportionality relationship between the Sauter mean diameter $d_{32}$ and the maximum diameter is often assumed. This relationship is very important to use Kolmogoroff's turbulence theory that relates the maximum diameter to the mean energy dissipation rate.

In order to check this relationship the $d_{90}$ is used instead of the $d_{\max }$ because it is measured with more confidence by the laser diffraction used here.

Fig. 13 represents $d_{90}$ versus $d_{32}$ for the Water/PVA/Toluene $\left(S_{3}\right)$ system at different flowrates and for a dispersed phase ratio $\Phi$ ranging from 0.10 to 0.50 . The $d_{90} / d_{32}$ ratio is constant and equal to 2 .

Fig. 14 represents the evolution of $d_{90}$ as a function of $d_{32}$ for the four systems at $\Phi=0.25$. The proportionality coefficient

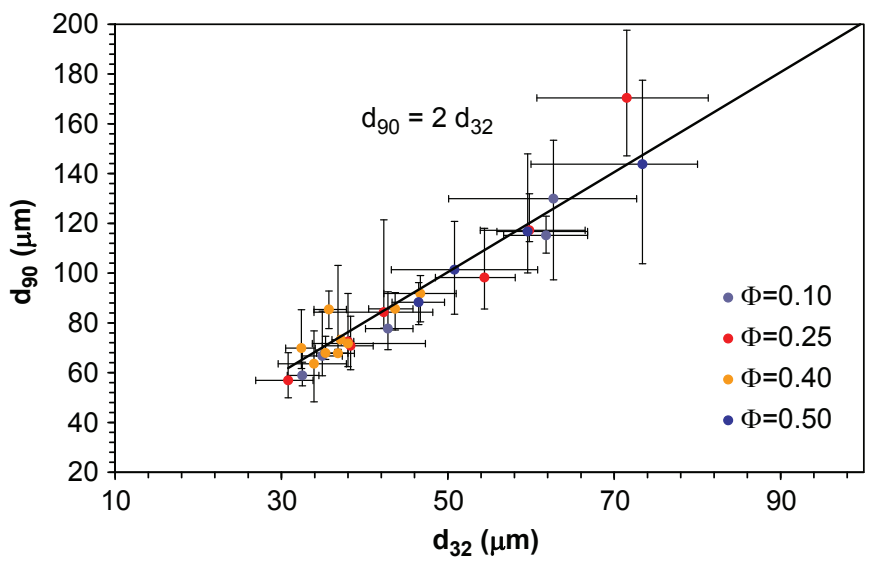

Fig. 13. $d_{90}$ as a function of $d_{32}$ for the Water/PVA/Toluene system $\left(S_{3}\right)$.

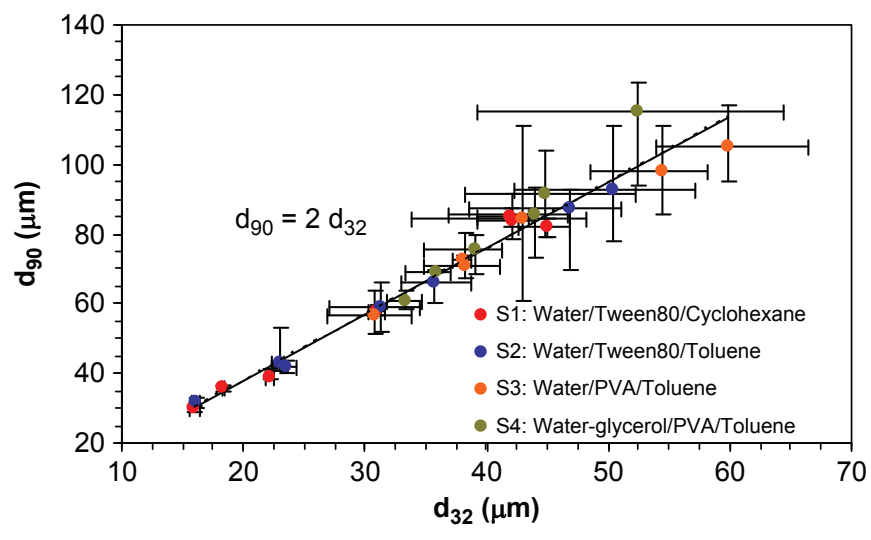

Fig. 14. $d_{90}$ as a function of $d_{32}$ for the four systems at $\Phi=0.25$.

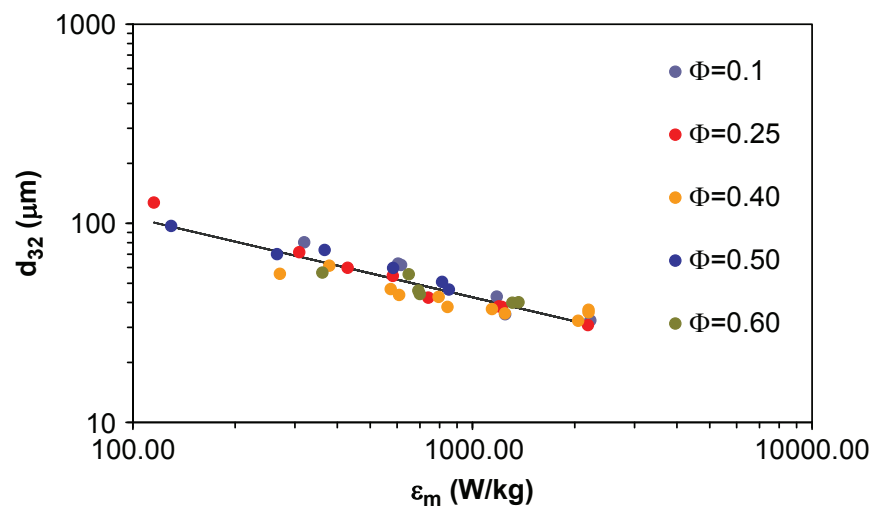

Fig. 15. Sauter mean diameters as a function of mean energy dissipation rate per fluid mass unit for the Water/PVA/Toluene system $\left(S_{3}\right)$ at different dispersed phase concentration $\Phi$.

between $d_{90}$ and $d_{32}$ is constant and equal to about 2 for the four systems.

As a conclusion $d_{90}$ is quite proportional to $d_{32}$ for the four systems tested. So even if the proportionality is not strictly checked between $d_{\max }$ and $d_{32}$ these results allow to propose correlations predicting Sauter mean diameters as characteristic diameters.

\subsubsection{Relationship between $d_{32}$ and mean energy dissipation rate}

The relationship between experimental $d_{32}$ and corresponding mean energy dissipation rates per fluid mass unit $\varepsilon_{m}$ is evaluated in order to discuss the validity of Kolmogoroff's theory of turbulence. Experimental data obtained with the Water/PVA/ Toluene system $\left(S_{3}\right)$ at different dispersed phase concentrations are plotted in Fig. 15 and experimental data obtained with the four systems at $\Phi=0.25$ are reported in Fig. 16 .

For each data series the $d_{32}$ are well linearly related to $\varepsilon_{m}^{-0.4}$ in logarithmic representation. These values show that Kolmogoroff's theory of turbulence fits rather well with experimental data whatever the dispersed phase concentration until phase inversion. So this indicates that the turbulence flow field generated by the SMV mixer is rather homogeneous and isotropic even if some slight discrepancies can be noticed, especially for the systems $S_{1}$ and $S_{2}$. It can be assumed that the break-up conditions are not completely of "Kolmogoroff" type, i.e. governed by the smallest eddies size. It is also possible that a "jet effect" due to the dispersed phase introduction through the centre of the mixer influences the break-up mechanism a little and especially at high dispersed phase concentration. In fact in the tested conditions 


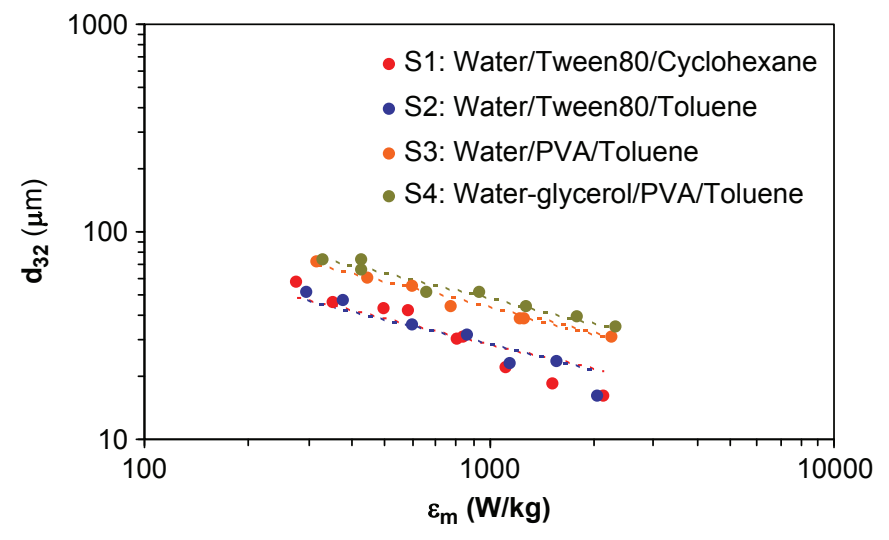

Fig. 16. Sauter mean diameters as a function of mean energy dissipation rate per fluid mass unit for the four systems tested with $\Phi=0.25$.

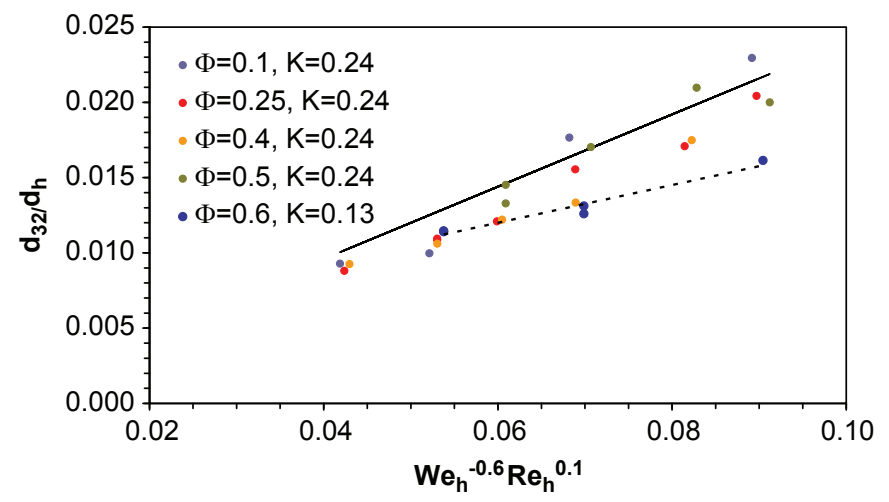

Fig. 17. Correlation of experimental data through Middleman's correlation for the Water/PVA/Toluene system $\left(S_{3}\right)$.

the ratio of the dispersed phase velocity to the continuous phase velocity ranges from 0.7 to 6.3 when the dispersed phase concentration increases.

Fig. 16 also enables comparison of the influence of surfactant as well as viscosity and density ratios on $d_{32}$. This comparison is more relevant than that proposed in Section 4.2.2 as it takes into account the energy consumption of the operation. Fig. 16 shows that mean droplet sizes are lower when the Tween80 is involved. Moreover for the two systems involving PVA, $d_{32}$ are lower when $\rho_{d} / \rho_{c}$ as well as $\mu_{d} / \mu_{c}$ increase. Thus as highlighted in Section 4.2.2 the interfacial tension between both phases is the most important physico-chemical parameter on the break-up phenomenon. Moreover, the density and viscosity ratios have little influence on the result of the operation.

\subsubsection{Correlation of experimental data as a function of dimensionless numbers}

Assuming Kolmogoroff's theory of turbulence and the Blasius type dependence of the Fanning friction factor towards the Reynolds number, experimental Sauter diameters of the present study are correlated as a function of hydraulic Weber and Reynolds numbers as proposed by Middleman (1974)

$\frac{d_{32}}{d_{h}}=K \mathrm{We}_{h}{ }^{-0.6} \mathrm{Re}_{h}^{0.1}$

where the hydraulic Weber number $\mathrm{We}_{h}$ is calculated as follows:

$\mathrm{We}_{h}=\frac{\rho V_{0} D_{h}}{\varepsilon \sigma}$

In order to calculate the hydraulic Weber number according to Eq. (23) the interfacial tension between both phases is calculated

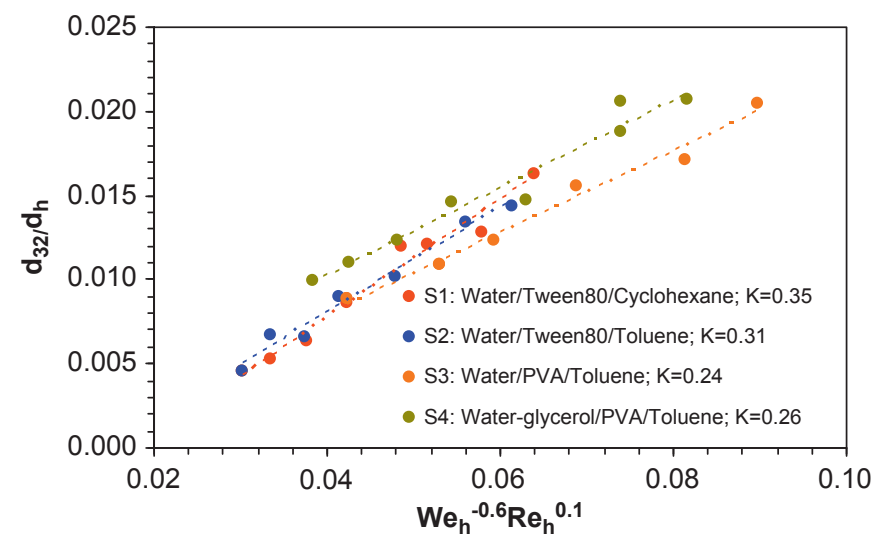

Fig. 18. Correlation of experimental data through Middleman's expression for the four systems tested with $\Phi=0.25$.

according to a phenomenological model (Lobry et al., submitted for publication) at a time corresponding to half the residence time in the mixer.

Figs. 17 and 18 show that except for the Water/PVA/Toluene system $\left(S_{3}\right)$ at $\Phi=0.60$ the results fit well with Eq. (22). $d_{32}$ obtained with the four different systems are also well predicted through the correlation proposed by Middleman. The $K$ values obtained for systems involving the same surfactant $\left(S_{1}\right.$ and $S_{2}, S_{3}$ and $S_{4}$ ) are similar: respectively, 0.35 and 0.31 for the systems with Tween 80 , and, respectively, 0.24 and 0.26 for the systems $S_{3}$ with PVA. So it appears that the $K$ value mainly depends on the surfactant used.

Moreover the comparison between systems $S_{3}$ and $S_{4}$ under similar hydrodynamic conditions points out that larger mean droplet sizes are obtained with the system $S_{4}$. This may be due to the viscosity ratio difference between both systems.

\section{Conclusion}

From an analytical point of view, a good agreement is obtained for both analytical techniques employed for all the systems and the dispersed phase concentrations investigated. The On-line Turbiscan allows to measure with enough accuracy the mean droplet size and the influence of different operating parameters on the mean droplet size could be directly studied despite the high dispersed phase concentration conditions.

Contrary to previous works which consider the interfacial tension value at equilibrium, the dimensionless hydraulic Weber number $\mathrm{We}_{h}$ used in our correlation is calculated by using half the residence time in the mixer. So it better represents the result of the break-up phenomenon in static mixers.

The pressure drop for two-phase flow is modelled. For the four systems a correlation based on the Blasius law established for single phase flow fits well with experimental results whatever the dispersed phase concentration.

The effect of the dispersed phase concentration was investigated for the Water/PVA/Toluene system $\left(S_{3}\right)$. It seems that until $\Phi=0.60$ the dispersed phase concentration has no effect on the mean diameter. At $\Phi=0.60$ the distribution is larger and the system is more complex than the classical oil in water system obtained at lower dispersed phase concentrations. Moreover from $\Phi=0.60$ the pressure drop increases. It is thus assumed that a phase inversion phenomenon would occur for a dispersed phase concentration slightly higher than 0.60 .

The relationship between Sauter mean diameters and the mean energy dissipation rate per fluid mass unit enables the 
conclusion that Kolmogoroff's theory of isotropic turbulence is verified for all the tested operating conditions until $\Phi=0.50$.

Based on these observations the experimental results can be modelled by using Middleman's correlations under turbulent flow which takes into account two dimensionless numbers, the hydraulic Reynolds number $\operatorname{Re}_{h}$ and the hydraulic Weber number $\mathrm{We}_{h}$ in which the interfacial tension value is expressed at half the residence time in the mixer. It is the nature of the surfactant which controls the mean droplet size.

Finally, this work demonstrates the low effect of the dispersed phase concentration until the system becomes more complex and approaches the phase inversion phenomenon. It appears that the main physico-chemical parameter which controls the break-up phenomenon in static mixers is the nature of the surfactant and especially its diffusion kinetics. The correlation to predict the mean droplet size through dimensionless parameters is improved here by taking into account the interfacial tension value at a time of the order of the residence time in the mixer.

\section{Acknowledgments}

The authors thank the Sulzer Chemtech Company and especially Dr. Philip Nising, Dr. Sebastian Hirschberg and Dr. Patrick Farquet for their technical support.

\section{References}

Al Taweel, A.M., Walker, L.D., 1983. Liquid dispersion in static in line mixers. Can. J. Chem. Eng. 61, 527-533.

Al Taweel, A.M., Chen, C.A., 1996. A novel static mixer for the effective dispersion of immiscible liquids. Trans. IchemE 74 (Part A), 445-450.

Angle, C.A., Dabros, T., Hamza, H.A., 2006. Predicting the sizes of toluene-diluted heavy oil emulsions in trubulent flow part 1:application of two adsorption kinetic models for $\sigma \mathrm{E}$ in two size predictive models. Chem. Eng. Sci. 61 (2), 7309-7324.

Angle, C.A., Hamza, H.A., 2006. Predicting the sizes of toluene-diluted heavy oil emulsions in trubulent flow part 2: Hinze-Kolmogorov based model adapted for increased oil fraction and energy dissipation in a stirred tank. Chem. Eng. Sci. 61, 7325-7335.

Berkman, P.D., Calabrese, R.V., 1988. Dispersion of viscous liquids by turbulent flow in a static mixer. AIChE J. 34 (4), 602-609.

Bohnet, M., Kalbitz, H., Németh, J., Pazmany, J., 1990. Improvement of forced convection heat transfer by using static mixers. In: Proceedings of the International ACT Conference, INTC, Jerusalem, pp. 315-320.

Boscher, V., Helleboid, R., Lasuye, T., Stasik, B., Riess, G., 2009. On-line acoustic attenuation spectroscopy of emulsions stabilized by vinyl alcohol acetate copolymers: a model system for the suspension polymerization of vinyl chloride. Polym. Int. 58, 1209-1216.

Buron, H., Mengual, O., Meunier, G., Cayré, I., Snabre, P., 2004. Review Optical Characterization of concentrated dispersions: applications to laboratory analyses and on-line process monitoring and control. Polym. Int. 53, 1205-1209.

Chandra, K.G., Kale, D.D., 1995. Pressure drop for two-phase air-non-Newtonian liquid flow in static mixers. Chem. Eng. J. 59, 277-280.

Chen, S.J., Libby, D.R., 1978. Gas liquid and liquid-liquid dispersions in a Kenics mixer. In: Proceedings of the 71st Annual AIChE Meeting.

Chesters, A.K., 1991. The modelling of coalescence processes in fluid-liquid dispersions: a review of current understanding. Trans. IChemE 69 (part A), 259-270.

Coulaloglou, C.A., 1975. Dispersed Phase Interactions in an Agitated Vessel. Ph.D. Thesis. Illinois Institute of Technology, Chicago.

Cull, S.G., Lovick, J.W., Lye, G.J., Angeli, P., 2002. Scale-down studies on the hydrodynamics of two-liquid phase biocatalytic reactors. Bioprocess Biosyst. Eng. 25, 143-153.

Das, P.K., Legrand, J., Morançais, P., Carnelle, G., 2005. Drop breakage model in static mixers at low and intermediate Reynolds number. Chem. Eng. Sci. 60, 231-238.

De, B., Mandal, T.K., Das, G., 2010. Experimental studies on phase inversion in a small diameter horizontal pipe. Chem. Eng. Res. Des. 88, 819-826.

Desnoyer, C., Masbernat, O., Gourdon, C., 2003. Experimental study of drop size distributions at high dispersed phase ratio in liquid-liquid dispersions. Chem. Eng. Sci. 58, 1353-1363.

Haas, P.A., 1987. Turbulent dispersion of aqueous drops in organic liquid. AIChE J. 33, 987-995.
Heyouni, A., Roustan, M., Do-Quang, Z., 2002. Hydrodynamics and mass transfer in gas-liquid flow through static mixers. Chem. Eng. Sci. 57, 3325-3333.

Hirschberg, S., Koubek, R., Moser, F., Schöck, J., 2009. An improvement of the Sulzer SMX static mixer significantly reducing the pressure drop. Chem. Eng. Res. Dev. 87, 524-532.

Ioannou, K., Nydal, O.J., Angeli, P., 2005. Phase inversion in dispersed liquid liquid flows. Exp. Therm. Fluid Sci 29, 331-339.

Kalbanov, A.S., Makarov, K.N., Pertzov, A.V., Shchukin, E.D., 1990. Ostwald ripening in emulsions. J. Colloid Interface Sci. 138, 98-104.

Lan, L., Matar, O.K., Lawrence, C.J., Hewitt, G.F., 2006. Laser-induced fluorescence (LIF) studies of liquid-liquid flows. Part I: flow structures and phase inversion. Chem. Eng. Sci. 61, 4007-4021.

Legrand, J., Morancais, P., Carnelle, J., 2001. Liquid-liquid dispersion in a SMX-Sulzer static mixer. Inst. Chem. Eng. 79 (part A), 949-956.

Lemenand, T., Zellouf, Y., Della Valle, D., Peerhossaini, H. 2001. Formation de gouttelettes dans un mélange turbulent de deux fluides immiscibles (Droplet formation in the turbulent mixing of two immiscible fluids). In : 15ème Congr. Fr. Méc., Nancy 3-7 septembre, pp. 494-499.

Lemenand, T. Della Valle, D., Zellouf, Y., Peerhossaini, H. 2003. Droplet formation in turbulent mixing of two immiscible fluids in a new type of static mixer. Int. J. Multiphase Flow 29, 813-840.

Lemenand, T., Dupont, P., Della Vallee, D., Peerhossaini, H., 2005. Turbulent mixing of two immiscible fluids. Trans. Am. Soc. Mech. Eng. 127, 1132-1139.

Levich, V.G., 1962. Physiochemical Hydrodynamics. Prentice Hall, Englewood Cliffs, NJ 464

Li, H.Z., Fasol, C., Choplin, L., 1997. Pressure drop of Newtonian and non-Newtonian fluids across a Sulzer SMX static mixer. Trans. IchemE 75 (part A), 792-796.

Lobry, E., Theron, F., Gourdon, C., Le Sauze, N., Xuereb, C. Emulsification in continuous processes : needs for a methodology for acquisition of transient interfacial tension. Chem. Eng. Res. Des., submitted for publication.

Matsumura, K., Morishima, Y., Masuda, K., Ikenaga, H., 1981. Some performance data of the Hi-Mixer-An In-line mixer. Chem. Ing. Tech. 53 (1), 51-52.

Middleman, S., 1974. Drop size distributions produced by turbulent pipe flow of immiscible fluids through a static mixer. Ind. Eng. Chem. Process Des. Develop. 13 (1), 78-83.

O'Rourke, A.M., MacLoughlin, P.F., 2005. A comparison of measurement techniques used in the analysis of evolving liquid liquid dispersion. Chem. Eng. Proc. $44,885-894$.

Pizzino, A., Catté, M., Van Hecke, E., Salager, J.L., Aubry, J.M., 2009. On-line backscattering tracking of the transitional phase inversion of emulsions. Colloids Surf. A: Physicochem. Eng. Aspects 338, 148-154.

Rama Rao, N.V., Baird, M.H.I., Hrymak, A.N., Wood, P.E., 2007. Dispersion of highviscosity liquid-liquid systems by flow through SMX static mixer elements. Chem. Eng. Sci. 62, 6885-6896.

Ritter, J., Kraume, M., 2000. Communication-On-line measurement technique for drop size distribution in liquid/liquid systems at high dispersed phase fractions. Chem. Eng. Technol. 23 (7), 579-581.

Shah, N.F., Kale, D.D., 1991. Pressure drop for laminar flow of non-newtonian fluids in static mixers. Chem. Eng. Sci. 46 (8), 2159-2161.

Shah, N.F., Kale, D.D., 1992a. Pressure drop for laminar flow of viscoelastic fluids in static mixers. Chem. Eng. Sci. 47 (8), 2097-2100.

Shah, N.F., Kale, D.D., 1992b. Two-phase, gas-liquid flows in static mixers. AIChE J. 38 (2), 308-310.

Streiff, F.A., 1977. In-line dispersion and mass transfer using static mixing equipment. Sulzer Technol. Rev., 108-113.

Streiff, F.A., Mathys, P., Fisher, T.U., 1997. New fundamentals for liquid-liquid dispersion using static mixers. Réc. Progr. Génie Proc. 11, 307-314.

Tadros, T.F., Vincent, B., 1983. Encyclopedia of Emulsion Technology. Paul Becher Edition, 1. Marcel Dekker, New York.

Taylor, G.I., 1935. The viscosity of a fluid containing small drops of another fluid. Proc. Roy. Soc. A 138, 41-48.

Thakur, R.K., Vial, Ch., Nigam, K.D.P., Nauman, E.B., Djelveh, G., 2003. Static mixer in the process industries-a review. Trans. IChemE 81 (part A), 787-826.

Theron, F., Le Sauze, N., Ricard, A., 2010. Turbulent liquid-liquid dispersion in Sulzer SMX mixer. Ind. Eng. Chem. Res. 49, 623-632.

Theron, F., Le Sauze, N., 2011. Comparison between three static mixers for emulsification in turbulent flow. Int. J. Multiphase Flow. 37 (5), 488-500.

Tidhar, M., Merchuk, J.C., Sembira, A.N., Wolf, D., 1986. Characteristics of a motionless mixer for dispersion of immiscible fluids-II. Phase inversion of liquid-liquid systems. Chem. Eng. Sci. 41 (3), 457-462.

Turunen, I., 1994. Mass transfer in tubular reactors equipped with static mixers. Chem. Eng. Sci. 49 (24B), 5257-5269.

Yamamoto, T., Kawasaki, H., Kumazawa, H., 2007. Relationship between the dispersed droplet diameter and the mean power input for emulsification in three different type of motionless mixers. J. Chem. Eng. Jpn. 40, 673-678.

Yarranton, H.W., Masliyah, J.H., 1997. Numerical simulation of Ostwald ripening in emulsions. J. Colloid Interface Sci 196, 157-169. 